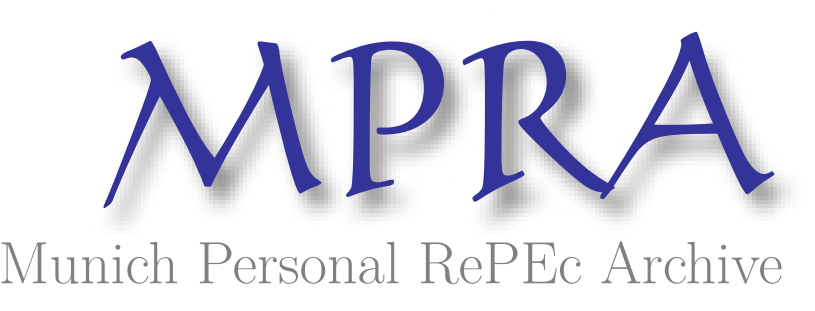

\title{
Disclosure Quality, Cost of Capital, and Investors' Welfare
}

Gao, Pingyang

The University of Chicago - Graduate School of Business

January 2008

Online at https://mpra.ub.uni-muenchen.de/9478/

MPRA Paper No. 9478, posted 08 Jul 2008 00:40 UTC 


\title{
Disclosure Quality, Cost of Capital, and Investors' Welfare*
}

\author{
Pingyang $\mathrm{Gao}^{\dagger}$ \\ The University of Chicago Graduate School of Business
}

July 7, 2008

\begin{abstract}
It is widely believed that disclosure quality improves investors' welfare by reducing cost of capital in a competitive market. This paper examines this conventional wisdom by studying a production economy in which disclosure influences a firm's investment decisions. I demonstrate three points. First, cost of capital could increase with disclosure quality when new investment is sufficiently elastic. Second, there are plausible conditions under which disclosure quality reduces the welfare of current and/or new investors. Finally, cost of capital is not a sufficient statistic for the effects of disclosure quality on the welfare of either current or new investors. These results may help interpret the mixed empirical findings on the relation between disclosure quality and cost of capital, inform the empirical efforts to measure the economic consequences of accounting disclosure, and add to the ongoing debate on the reform of financial reporting and disclosure regulation.
\end{abstract}

${ }^{*}$ This paper is part of my dissertation at Yale University. I sincerely thank my advisers, Rick Antle, John Geanakoplos, Brian Mittendorf, and Shyam Sunder (Chair), for their guidance and encouragement. I also thank Thomas Hemmer, Bjorn Jorgensen, Dong Lou, Robert E. Verrecchia, and Winnie Wen for many inspiring discussions. The paper has been substantially improved by the constructive suggestions I have received from the workshops at Carnegie Mellon University, Columbia, CUNY Baruch, Dartmouth, Duke, New York University, Northwestern University, University of Chicago, University of Houston, University of Minnesota, University of Toronto, University of Pennsylvania, Yale, and the AAA 2008 Financial Accounting and Reporting Section meeting. In addition, I am grateful for the generous financial support of the Deloitte Foundation.

${ }^{\dagger}$ Email: pingyang.gao@chicagogsb.edu 


\section{Introduction}

Regulators and firms are concerned about the welfare impact of ex ante disclosure policies. Because it is difficult to empirically measure investors' welfare, a great deal of recent efforts have focused on the relation between disclosure quality and cost of capital, as an intermediate step to the ultimate goal of understanding the welfare impact of accounting disclosure. For example, Arthur Levitt, the former chairman of the Securities and Exchange Commission, has claimed, "The truth is, high [accounting] standards lower the cost of capital. And that's a goal we share"(Levitt (1998)). This remark, as well as similar arguments pervasive in policy discussions, has been frequently cited as the motivation for studying the relation between disclosure quality and cost of capital. One interpretation of this remark is that cost of capital summarizes the impact of disclosure quality on investors' welfare. This paper explicitly examines this underlying conventional wisdom.

Moreover, even on the relation between disclosure quality and cost of capital, there has been a gap between the empirical evidence and theoretical research. While the empirical findings on the relation have been disturbingly mixed, as surveyed by Healy and Palepu (2001) and Leuz and Wysocki (2007), most theoretical studies have examined a competitive pure exchange economy and predicted that disclosure quality monotonically reduces cost of capital. Although empirical challenges may have contributed to the inconsistent empirical findings, such as the self-selection problem and the measurement errors in proxies for cost of capital and disclosure quality, nonetheless, this paper provides one theoretical explanation for the mixed empirical relation, by introducing the investment effect of disclosure.

In sum, I address two questions in this paper. First, how does disclosure quality affect cost of capital, current investors' welfare, and new investors' welfare when disclosure influences a firm's investment decisions? Second, whether is the cost of capital as used in the literature a sufficient statistic for the impact of disclosure quality on the welfare of current and/or new investors? I first construct an economy in which disclosure affects a firm's investment decisions by influencing investors' valuations. Then, I identify the necessary and sufficient conditions under which disclosure quality reduces cost of capital and improves the welfare of current and new investors. Finally, I compare these conditions to show that they are not equivalent, nor do they subsume each other. Therefore, cost of capital is not a sufficient statistic for the welfare of either current or new investors in the analysis of the economic consequences of disclosure quality.

Disclosure affects the firm's investment decisions by revealing its information to the market. Such information revelation influences investors' beliefs and valuations which in turn guide the firm's investment. 
The firm's investment decisions affect the stock price, and the stock price has feedback effect on the firm's investment choices. In a rational expectations equilibrium, both the investment decisions and the valuation decisions are determined consistently.

The investment effect of disclosure is instrumental in its impact on cost of capital. Disclosure reduces investors' uncertainty about the firm's marginal profitability and thus they would like to pay a higher price for the firm's shares on average. Given the fixed investment, higher price implies lower cost of capital. That would be the end of the story in a pure exchange economy and we could conclude that disclosure quality monotonically reduces cost of capital. However, when new investment is possible, as in my model, resolution of uncertainty of the firm's marginal profitability also guides the firm to adjust its investment level and leads to a higher level of investment on average. As a result, both the investment base and the marginal profitability of per unit investment are affected by disclosure quality. A priori, it is not clear whether the cost of capital, a measure of per dollar risk premium, is higher or lower in equilibrium. The first result of the paper shows that cost of capital increases with disclosure quality if and only if the adjustment cost of new investment is sufficiently low and the prior expected profitability of existing investment is sufficiently high.

The investment effect is also important for the welfare consequences of disclosure quality. In a pure exchange economy, disclosure does not eliminate risk in the economy; instead, it only substitutes the price risk for the cash flow risk and thus allocates the risk between current and new investors (e.g., Hirshleifer (1971) and Dye (1990)). For current investors, disclosure creates a trade-off between a higher average level and a higher volatility of the stock price. When current investors are sufficiently risk averse relative to new investors, disclosure quality makes current investors worse off by preventing them from transferring more risk to new investors. In a production economy, however, disclosure also influences the firm's investment decisions which affects investors' welfare. The second result of the paper demonstrates that current investors are worse off with higher disclosure quality if and only if current investors are sufficiently risk averse relative to new investors and the adjustment cost of new investment is sufficiently high. Current investors' high risk aversion guarantees that the risk allocation effect decreases their welfare and the high adjustment cost of new investment ensures that the investment effect is too marginal to offset the adverse risk allocation effect.

Finally, disclosure quality always makes new investors worse off in the pure exchange economy. New investors gain surplus from trading by contributing their risk tolerance to the market. Early resolution of uncertainty reduces the amount of risk left in the market and thus decreases the demand for their risk-taking capacity. As a result, they gain less surplus from bearing risk for current investors. In the presence of the investment effect, the overall risk of the firm's cash flow is a function of both the risk of per-unit investment 
and the total investment. While disclosure reduces the risk of per-unit investment, it could increase the total investment. The third result of the paper reveals that disclosure reduces new investors' welfare if and only if both the adjustment cost of new investment and the level of existing investment are sufficiently high.

The above analysis reveals that the economic forces behind the impacts of disclosure quality on cost of capital, current investors' welfare, and new investors' welfare are different and do not subsume each other. Therefore, cost of capital is not a sufficient statistic for the welfare of either current or new investors. In particular, disclosure quality could increase cost of capital when it increases the overall risk of the firm's cash flow. Such an endogenous increase in risk could benefit current investors if it is accompanied by a simultaneous increase in the level of the firm's cash flow, and could benefit new investors as well because it makes their risk tolerance more valuable.

The results have a number of implications for policy discussions and empirical studies. The conventional wisdom that disclosure quality improves investors' welfare by reducing cost of capital could fail in two aspects. Neither does disclosure quality monotonically reduce cost of capital in the presence of the investment effect, nor is lower (higher) cost of capital necessarily associated with higher (lower) welfare for either current or new investors. The model has three major implications for empirical studies. First, we should be careful in drawing prescriptive suggestions from the research on the relation between disclosure quality and cost of capital. Second, we may sort out the mixed empirical findings on the relation between disclosure quality and cost of capital if we take into account the investment effect of disclosure. Finally, the intensity of the investment effect is an important determinant of the firm's disclosure policy. Firms with lower adjustment cost of new investment is more likely to commit to higher disclosure quality in order to maximize current investors' welfare. Similarly, exchanges and legal regimes with differential requirements of disclosure attract different groups of firms based on their flexibility of investment. The key to testing these predictions is to measure the adjustment cost of new investment, the proxy for the intensity of the investment effect in the model. Verdi (2006) and Hope and Thomas (2008) have begun to empirically characterize how disclosure quality influences the firm's investment efficiency.

The rest of the paper proceeds as follows. Section 2 reviews three related lines of research; Section 3 develops the model and studies the effect of disclosure quality on the distribution of the firm's cash flow. Section 4 examines and compares the impacts of disclosure quality on cost of capital, current investors' welfare, and new investors' welfare. Section 5 explores a number of empirical implications of the results. Section 6 discusses some possible extensions. Section 7 concludes. All proofs are in the appendix. 


\section{Related Literature}

In terms of modeling, this study synthesizes three somewhat separate lines of research on disclosure: the link between disclosure quality and cost of capital, the welfare consequences of disclosure, and the real effect of disclosure.

First, this paper extends the research on the relation between disclosure quality and cost of capital from a pure exchange economy to a production economy (e.g., Easley and O'Hara (2004); Yee (2006); Lambert, Leuz, and Verrecchia (2006, 2007); Hughes, Liu, and Liu (2007); Christensen, De La Rosa, and Feltham (2008)). A common theme in previous literature is that disclosure quality reduces cost of capital by reducing the conditional variance (or covariance) of the firm's future payoffs in a pure exchange economy. One exception is Lambert, Leuz, and Verrecchia (2007) who also study the indirect effect of disclosure. They point out that cost of capital may increase with disclosure quality if disclosure changes the firm's real decisions and thus changes both the mean and variance of the firm's cash flow. However, they do not link this result directly to disclosure quality. Building on their insight, I study the investment effect and identify conditions for a positive relation between disclosure quality and cost of capital.

Moreover, the results in this paper complements those in Christensen, De La Rosa, and Feltham (2008). Following the previous literature, I use the ex post cost of capital in a production economy to demonstrate the results; they show that in a pure exchange economy disclosure quality does not affect ex ante cost of capital and that ex ante cost of capital does not measure welfare either.

In addition, the finding about the discrepancy between cost of capital and investors' welfare reconciles the intuition in Easley and O'Hara (2004) with the results in Lambert, Leuz, and Verrecchia (2006). The latter paper demonstrates that cost of capital in a competitive market is determined by investors' average information precision, not by information asymmetry per se as claimed in Easley and O'Hara (2004). Nonetheless, the intuition in Easley and O'Hara (2004) that information asymmetry puts uninformed investors on the wrong side of trading is still appealing. The reconciliation lies in the conclusion of this paper that cost of capital is not monotonically related to investors' welfare. Reduction in information asymmetry improves uninformed investors' welfare relative to informed investors', as advocated in Easley and O'Hara (2004), although it does not directly affect cost of capital, as shown in Lambert, Leuz, and Verrecchia (2006).

Second, this paper contributes to the broad literature on the efficiency of disclosure quality by examining the investment effect of disclosure. The welfare impact of an ex ante disclosure policy in general is ambigu- 
ous. ${ }^{1}$ In a capital market setting, a central result is that the combination of pure exchange, constant absolute risk aversion (CARA), and perfect competition leaves little room for studying investors' welfare. ${ }^{2}$ Subsequent research introduces private information acquisition (e.g., Diamond (1985)), relaxes the assumption of perfect competition (e.g., Kyle (1985); Diamond and Verrecchia (1991); Baiman and Verrecchia (1996)), or incorporates production use of information (e.g., Kunkel (1982); Christensen and Feltham (1988); Pae $(1999,2002)$; Yee (2007).). ${ }^{3}$ While it fits into the last category, my paper differs from Yee (2007) in that disclosure affects the firm's investment decisions in my paper but only influences investors' inter-temporal allocation decisions in Yee (2007).

As Diamond and Verrecchia (1991) and Lambert, Leuz, and Verrecchia (2006) point out, the conventional wisdom that disclosure mitigates adverse selection among investors can not be studied in the setting of pure exchange, CARA, and perfect competition. They relax the assumption of perfect competition to allow disclosure to "level the playground" among investors and thus to affect cost of capital. This paper keeps the assumption of perfect competition but breaks away from the assumption of pure exchange to study the consequences of disclosure quality for the cost of capital and investors' welfare.

In addition, my paper extends Dye (1990) by expanding the welfare effect of disclosure to a production economy. Although both Dye (1990) and Dye and Sridhar (2007) also consider the real effect of disclosure, they directly assume how disclosure quality changes the distribution of the firm's cash flow.

Finally, this paper draws heavily on the research about the real effect of disclosure in capital market. A firm's disclosure influences investors' perceptions which in turn guide the firm's real decisions, and both the investors' perceptions and the firm's real decisions are consistently determined in a rational expectations equilibrium. This notion, developed by Kanodia (1980), has been used to study the effect of periodical performance reports (e.g., Kanodia and Lee (1998)), measuring intangibles (e.g., Kanodia, Sapra, and Venugopalan (2004)), and accounting for derivatives (e.g., Melumad, Weyns, and Ziv (1999); Kanodia, Mukherji,

\footnotetext{
${ }^{1}$ While more information is always useful in a single-person single-period decision making, the value of accounting disclosure in a multi-person or/and multi-period setting is much less clear. For example, mandating more disclosure could reduce a firm's value by altering market competition (e.g., Verrecchia (1983)) or reduce the principal's welfare in a principal-agent relation (e.g., Dye (1988); Arya, Glover, and Sunder (1998, 2003)).

${ }^{2}$ Interested readers are referred to Wilson (1968); Hirshleifer (1971); Hakansson, Kunkel, and Ohlson (1982); Milgrom and Stokey (1982); Dye (2001); Schlee (2001); Verrecchia (2001). Verrecchia (1982) and Watts (1982) survey this early literature. See also Holmstrom and Tirole (1993) and Dow and Rahi (2003) for the concern of the adverse welfare effect of public information in models in economics and finance.

${ }^{3}$ See Verrecchia (2001) and Dye (2001) for an inspiring discussion about the development of the literature.
} 
Sapra, and Venugopalan (2000); Sapra (2002); Sapra and Shin (2007)). ${ }^{4}$ The paper closely related to mine is Kanodia, Singh, and Spero (2005) who study the real effect of the imprecision in measuring investment in a risk neutral market. The imprecision allows the firm to use investment to convey its private information to market and thus improves the use of information in investment decisions. Given the different focuses, I abstract from the signaling game and elaborate on the market process that determines cost of capital and allocates risk.

\section{The Model and Equilibrium}

This section describes and solves the model. It is a disclosing-and-then-trading model that allows disclosure to influence the firm's investment. After solving for the unique equilibrium, I discuss four properties of the equilibrium and in particular examine how disclosure quality changes the characteristics of the distribution of the firm's cash flow.

\subsection{The Model}

I study a large economy to allow for risk sharing in a competitive market. The number of risky assets (firms) per capita is finite, although the number of both investors and risky assets could be infinite. Therefore, I could describe the model in terms of per capita without loss of generality. The risky shares of a representative firm are traded between current and new investors after disclosure and the number of shares per capita is normalized to be one. There is also a risk free asset, which acts as a numeraire and whose return is normalized to zero. Figure 1 describes the time line of events.

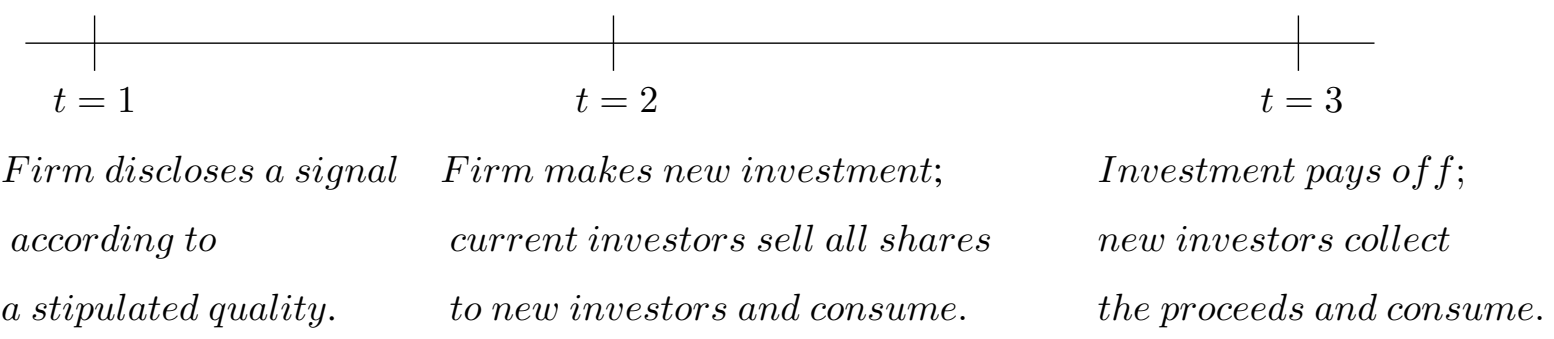

Figure 1: The Time Line of Events

\footnotetext{
${ }^{4}$ Another variant of the real effect further incorporates the Hayekian view that market price aggregates the diverse information among investors. The real effect then arises because disclosure interferes with agents' attempt to extract information from market price (e.g., Brennan and Schwartz (1982); Sunder (1989); Dye and Sridhar (2002)).
} 
At $\mathrm{t}=1$, the firm, which has $m$ units of existing investment, discloses a public signal about its marginal profitability, according to a pre-specified disclosure policy.

(New) Investors' prior belief about the marginal profitability is characterized by a mean $\mu_{0}$ plus a future innovation $\tilde{\mu}$. Before disclosure, they perceive that $\tilde{\mu}$ has a prior distribution of $N\left(0, \frac{1}{\alpha}\right)$. The disclosure, denoted by $\tilde{y}$, provides investors with an unbiased estimator of $\tilde{\mu}$, and takes the form as follows:

$$
\tilde{y}=\tilde{\mu}+\tilde{\epsilon}, \tilde{\epsilon} \sim N\left(0, \frac{1}{\beta}\right)
$$

where $\tilde{\epsilon}$ is independent of $\tilde{\mu}$. $\beta$ is the disclosure quality and the main variable of interest. As $\beta$ increases, the disclosure conveys better information to investors about the firm's marginal profitability. The paper focuses on the consequences of different level of $\beta$ for cost of capital and investors' welfare. Conditional on $y$, investors perceive that $\tilde{\mu}$ has a posterior distribution of $N(E[\tilde{\mu} \mid y], \operatorname{Var}[\tilde{\mu} \mid y])$ where $E[\tilde{\mu} \mid y]=$ $\frac{\beta}{\alpha+\beta} y, \operatorname{Var}[\tilde{\mu} \mid y]=\frac{1}{\alpha+\beta}$.

At $\mathrm{t}=2$, the firm makes additional investment $k$ to maximize its expected stock price, and then current investors sell their shares to new investors.

The net cash flow from $k$ units of new investment takes a quadratic form. Thus, new investors perceive that the firm's cash flow is as follows:

$$
\tilde{F}=m\left(\mu_{0}+\tilde{\mu}\right)+k \tilde{\mu}-\frac{z}{2} k^{2}
$$

For new investors, $\tilde{F}$ is the stochastic net cash flow at $t=3$, if the firm has $m$ units of existing investment and makes $k$ units of new investment at $t=2$. The first component $m\left(\mu_{0}+\tilde{\mu}\right)$ is the cash flow from the existing investment. The other component, $k \tilde{\mu}-\frac{z}{2} k^{2}$, is the net cash flow from the new investment $k .^{5} z$ is the adjustment cost of new investment; as we shall see soon, it captures the degree to which disclosure quality influences the firm's investment. ${ }^{6}$ Thus, $m, \mu_{0}$, and $z$ are fixed parameters, $k$ is the firm's choice variable, and $\tilde{\mu}$ is the only source of uncertainty in the firm's cash flow.

After the firm makes the new investment, current investors sell all of their shares to new investors in a competitive market, consume the proceeds, and leave the market. Based on the firm's disclosure and new

\footnotetext{
${ }^{5}$ Note that the net cash flow from new investment is independent of $\mu_{0}$, the prior expected profitability of existing investment. This choice highlights the idea that new investment will be made on the basis of new information $\tilde{\mu}$ and that the components of cash flow from new investment related to $\mu_{0}$ cancel out each other; that is, $k \tilde{\mu}-\frac{z}{2} k^{2}=k\left(\mu_{0}+\tilde{\mu}\right)-\left(k \mu_{0}+\frac{z}{2} k^{2}\right)$. This choice simplifies the math drastically. In addition, I assume that the profitability of existing and new investment are perfectly correlated. Relaxing this assumption to a less than perfect correlation does not qualitatively change the results.

${ }^{6}$ We could also interpret $z$ as a measure of the general economic outlook. By rescaling and rewriting the net cash flow from new investment as $k \frac{2}{z} \tilde{\mu}-k^{2}, \frac{1}{z}$ becomes a measure of the profitability of new investment.
} 
investment, new investors submit their demands for the firm's shares. Market clearing yields the stock price, which is the market valuation of the firm's stochastic cash flow $\tilde{F}^{7}$

At $t=3$, the firm's investment pays off, the firm is liquidated, and new investors consume.

Both current and new investors have CARA utility functions; that is, $U\left(W_{i}\right)=-\exp \left(-\frac{W_{i}}{\tau_{i}}\right), i \in\{c, n\}$. $\tau_{c}$ and $\tau_{n}$ are the coefficients of risk tolerance of current and new investors, respectively. The subscripts "c" and "n" represent "current investors" and "new investors".

Two assumptions warrant some discussion. The major assumption of the model is the overlappinggeneration setting. Current investors have to sell all of their shares of the firm after disclosure (due to life cycle reasons). This assumption is pervasive in studies of the capital market consequences of accounting information. The role of information in capital market is usually reflected in its influence on investors' trading behavior such as price and volume. However, information per se does not motivate trading in a complete market with common priors and rational expectations (e.g., Aumann (1976); Milgrom and Stokey (1982)). As a result, models of trading typically rely on some element of non-information related motivation, such as heterogeneous priors and liquidity reasons (e.g., Grossman and Stiglitz (1980); Diamond and Verrecchia (1981)). The life cycle reason for trading used in the overlapping generation model here is a similar modeling device and an extreme example of liquidity motivated trading. Given that current investors have to sell all of their shares after disclosure, it is reasonable to assume that the firm is motivated or monitored by current investors to choose investment level to maximize its stock price, which is equivalent to maximizing their welfare conditional on disclosure.

Another assumption is regarding the distribution of information among investors and between investors and the firm. To focus on the consequences of the investment effect, I assume no information asymmetry either among investors or between the firm and investors in the main model. That is, we could consider the model as the firm installing a public information system that produces public signal for all parties. However, the main results of the paper does not change if we use the concept that disclosure reveals information the firm has already owned. As I shall discuss in Section 6, introducing information asymmetry of either type does not alter the main results of the paper.

In sum, the two decisions to be made are how much new investment to make by the firm (or equivalently by current investors) and how many shares new investors want to bid. All parties observe all parameters, including existing investment level $m$, new investment level $k$, and the public signal $y$. For expositional

\footnotetext{
${ }^{7}$ Although I describe the investment and trading as two sequential steps, the order does not matter because rational expectations guarantee that the firm's investment decisions and new investors' valuation decisions are consistent in equilibrium.
} 
ease, I assume that all parameters are well defined. In particular, both the adjustment cost $z$ and the units of the existing investment $m$ are positive and bounded, except in three special economies defined later.

\subsection{The Equilibrium: Trading Price and Optimal Investment}

In this subsection, I solve for the unique equilibrium of the trading price and firm's optimal investment (Lemma 1). Then, I characterize the investment and risk allocation effects of disclosure and examine the impact of disclosure quality on the distribution of the firm's cash flow (Lemma 2). These metrics are the building blocks for the main discussion of the paper in the next section.

A rational expectations equilibrium is a pair of a trading price function $p(y)$ and an investment function $k(y)$, such that, for any signal $y$, the pair $(k(y), p(y))$ satisfies:

1. given $k(y), p(y)$ clears the market;

2. given the functional form of $p(y), k(y)$ maximizes $p(y)$.

Lemma 1 (The Equilibrium). For any signal $y$, the unique equilibrium $(k(y), p(y))$ is as follows:

$$
\begin{aligned}
& k(y)=\frac{E[\tilde{\mu} \mid y]}{z+\frac{2}{\tau_{n}} \operatorname{Var}[\tilde{\mu} \mid y]}-\frac{\frac{2}{\tau_{n}} \operatorname{Var}[\tilde{\mu} \mid y]}{z+\frac{2}{\tau_{n}} \operatorname{Var}[\tilde{\mu} \mid y]} m \\
& p(y)=E[\tilde{F} \mid(y, k(y))]-\frac{1}{\tau_{n}} \operatorname{Var}[\tilde{F} \mid(y, k(y))]
\end{aligned}
$$

While there are many interesting properties of this equilibrium, I focus on four of them: the investment effect, the risk allocation effect, the overall impacts of disclosure quality on the mean and variance of the firm's cash flow, and the distribution of the stock price. ${ }^{8}$

First, the adjustment cost of new investment $z$ measures the intensity of the investment effect. One proxy for the impact of disclosure on the firm's investment decisions is the unconditional variance of the firm's new investment $(\operatorname{Var}[k(y)])$.

$$
\operatorname{Var}[k(y)]=\frac{\operatorname{Var}[E[\tilde{\mu} \mid y]]}{\left(z+\frac{2}{\tau_{n}} \operatorname{Var}[\tilde{\mu} \mid y]\right)^{2}}=\frac{\operatorname{Var}[\tilde{\mu}]-\operatorname{Var}[\tilde{\mu} \mid y]}{\left(z+\frac{2}{\tau_{n}} \operatorname{Var}[\tilde{\mu} \mid y]\right)^{2}}
$$

\footnotetext{
${ }^{8}$ Note that the investment level could be negative in equilibrium. Negative level of new investment could be interpreted as cutting back current investment or a short position in case of securities investment. Introducing shutting down complicates the model mathematically without qualitative impact on the main results of the paper, because the notion that disclosure benefits investment decisions still preserves. One convenient way to avoid the negative level of new investment is to modify the cash flow function in equation 1 as $\tilde{F}=m\left(\mu_{0}+\tilde{\mu}\right)+k|\tilde{\mu}|-\frac{z}{2} k^{2}$. By using the absolute level of the disclosure, the firm could use the information in both directions without incurring negative investment.
} 
As disclosure quality $\beta$ increases, the remaining uncertainty about the marginal profitability $\operatorname{Var}[\tilde{\mu} \mid y]$ dissipates and the firm's investment becomes more aggressive. Since $\operatorname{Var}[k(y)]$ decreases monotonically in the adjustment cost $z$ (given disclosure quality $\beta$ ), $z$ measures the degree of the investment effect. When $z$ is infinitely large, the optimal investment level is always zero and the economy becomes the pure exchange economy.

Second, the risk allocation effect of disclosure quality is at work because the firm has $m$ units of existing investment. Since the investment effect interacts with the risk allocation effect, I focus on the "residual" risk allocation effect by keeping the total investment fixed. In the absence of the investment effect, disclosure quality does not eliminate the risk of the firm's cash flow; instead, it only allocates the risk between current and new investors. I term the ex ante uncertainty of the trading price $\operatorname{Var}[p(y)]=\operatorname{Var}[E[\tilde{\mu} \mid y]]$ the price risk, and the remaining uncertainty of the firm's cash flow $\operatorname{Var}[\tilde{\mu} \mid y]$ the cash flow risk. ${ }^{9}$ Current investors bear the price risk, and new investors take the cash flow risk in return for a risk premium. Disclosure quality substitutes the price risk for the cash flow risk. Figure 2 illustrates this risk allocation effect. ${ }^{10}$



Figure 2: The Risk Allocation Effect

I prefer the label " risk allocation" to "risk sharing". The essence of risk sharing in the sense of Wilson (1968) is that trading reduces the total risk by diversifying the idiosyncratic risk. Optimal risk sharing requires that all investors hold the same portfolio (the market portfolio) under certain conditions. Such risk sharing exists in an inter-temporal model. ${ }^{11}$ However, in an overlapping generation model, at any level of disclosure, the risk current investors face is independent of that new investors take. Thus, disclosure allocates the risk between current and new investors, but does not reduce the total risk.

\footnotetext{
${ }^{9}$ For simplicity, the total investment and the risk tolerance coefficient of new investors are normalized to be unit.

${ }^{10}$ See Dye (1990) for additional discussions of the risk allocation effect of disclosure quality. Dye (1990) analyzes the welfare impact of disclosure quality in the pure exchange economy, and does not link cost of capital to investors' welfare.

${ }^{11}$ For example, suppose two investors who have the same CARA utility are endowed with two risky assets, $\tilde{x}_{1}$ and $\tilde{x}_{2}$ respectively. Trading between them results in the allocation $\left(\frac{\tilde{x}_{1}+\tilde{x}_{2}}{2}, \frac{\tilde{x}_{1}+\tilde{x}_{2}}{2}\right)$. The total variance of this allocation is smaller than the initial sum of variance: $2 \operatorname{Var}\left[\frac{\tilde{x}_{1}+\tilde{x}_{2}}{2}\right]=\frac{\operatorname{Var}\left[\tilde{x}_{1}\right]+\operatorname{Var}\left[\tilde{x}_{2}\right]+2 \operatorname{Cov}\left[\tilde{x}_{1}, \tilde{x}_{2}\right]}{2} \leq \operatorname{Var}\left[\tilde{x}_{1}\right]+\operatorname{Var}\left[\tilde{x}_{2}\right]$.
} 
The presence of both the investment and risk allocation effects and the interaction between them make the model complicated. While I prove the main results of the paper for the general model, I also analyze three special economies to enhance the intuition for the general results. The first two special economies, the pure exchange economy and the economy with constant return to scale (the CRTS economy), represent two extreme cases of the investment effect; the third special economy, the economy without existing investment, isolates the investment effect from the risk allocation effect.

Definition 1. The pure exchange economy is an economy in which the firm can not change investment after disclosure. Mathematically, it is achieved by setting the adjustment cost of new investment $z$ to infinity. In addition, I normalize $m$ to one unit in this case. Thus, $\tilde{F}_{p e}=\lim _{z \rightarrow \infty, m \rightarrow 1} \tilde{F}=\mu_{0}+\tilde{\mu}$. The subscript "pe" stands for "pure exchange."

Definition 2. The CRTS economy is an economy in which the firm's new investment exhibits the property of constant return to scale. It is achieved by setting the adjustment cost of new investment $z$ to zero. Thus, $\tilde{F}_{c r t s}=\lim _{z \rightarrow 0} \tilde{F}=m\left(\mu_{0}+\tilde{\mu}\right)+k \tilde{\mu}$. The subscript "crts" stands for "constant return to scale."

Definition 3. The economy without existing investment is an economy in which the firm does not have existing investment before disclosure. It is achieved by setting the existing investment level $m$ to zero. Thus, $\tilde{F}_{w e}=\lim _{m \rightarrow 0} \tilde{F}=k \tilde{\mu}-\frac{z}{2} k^{2}$. The subscript "we" stands for "without endowment."

Third, having analyzed the investment effect and the risk allocation effect, now we are ready to examine the impact of disclosure quality on the distribution of the firm's cash flow. The conditional distribution of the firm's cash flow, $\tilde{F} \mid y$, is normal and depends on the realization of the signal $y$. To focus on the impact of ex ante disclosure quality, I look at the unconditional mean and variance of the firm's cash flow before the disclosure, denoted as $E$ and $V$ respectively. The unconditional stock price, denoted as $P$, is then a function of $E$ and $V$.

$$
\begin{aligned}
E & \equiv E[E[\tilde{F} \mid y]] \\
V & \equiv E[\operatorname{Var}[\tilde{F} \mid y]] \\
P & \equiv E[p(y)]=E-\frac{V}{\tau_{n}}
\end{aligned}
$$

$E, V$, and $P$ are taken expectations with respect to disclosure $y$. For simplicity, I call $E[\tilde{F} \mid y]$ and $\operatorname{Var}[\tilde{F} \mid y]$ the conditional mean and variance of the firm's cash flow, $E$ and $V$ the mean and the variance of the firm's cash flow, and $P$ the stock price, whenever there is no confusion. 
Lemma 2 (Disclosure Quality and Cash Flow Distribution ). As disclosure quality improves, both the mean of the firm's cash flow $(E)$ and the stock price $(P)$ increase, but the variance of the firm's cash flow $(V)$ increases if and only if the adjustment cost of new investment is sufficiently low $\left(z<z^{*}\right)$.

The cutoff $z^{*}$ is given in expression A-15 in the appendix.

The main point in Lemma 2 is that with the investment effect, disclosure quality changes both the mean and variance of the firm's cash flow, and that the variance of the firm's cash flow could increase with disclosure quality. Therefore, the investment effect is important for the economic consequences of disclosure quality, given that all the main variables of interest - cost of capital, current investors' welfare, and new investors' welfare - are related to the characteristics of the distribution of the firm's cash flow. The importance becomes more obvious when Lemma 3 reveals that the impact of disclosure quality on the distribution of the firm's cash flow varies dramatically in three special economies.

Lemma 3 (Disclosure Quality and Cash Flow Distribution in the Special Economies). As disclosure quality improves,

1. in the pure exchange economy, the mean is constant, the variance decreases, and the price increases;

2. in the CRTS economy, the mean, the variance, and the stock price all increase;

3. in the economy without existing investment, the mean and the stock price increase, but the variance increases if and only if the adjustment cost is sufficiently low $\left(z<\frac{2}{(\beta-\alpha) \tau_{n}}\right)$.

Table 1 summarizes Lemma 2 and Lemma 3, and Figure 3 illustrates Lemma 3.

Insert Table 1 here.

Pure Exchange Economy

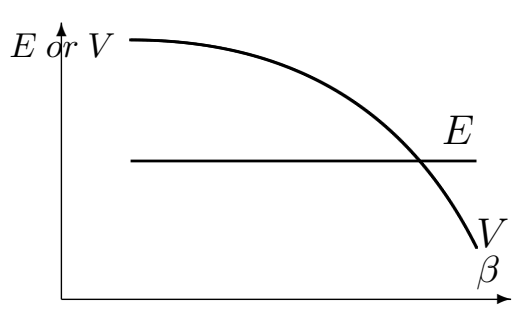

The CRTS Economy

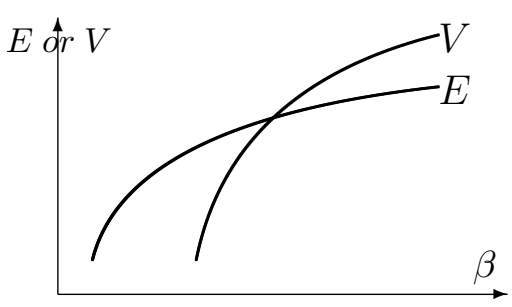

No Existing Investment
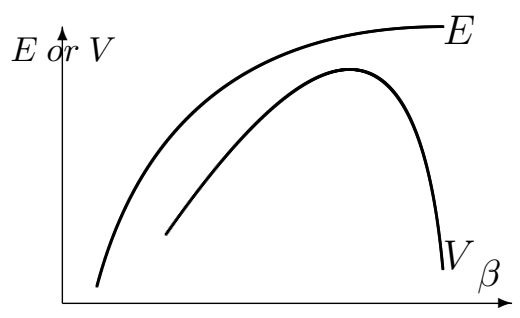

Figure $3:$ The Impacts of $\beta$ on $E$ and $V$ in Three Special Economies

Finally, the fourth property of the equilibrium I focus on is the distribution of the price $p(y)$. As given in equation A-6 in the appendix, $p(y)$ is non-linear in the signal $y$, and thus is not normally distributed. In 
fact, it has a Chi-square distribution. Economically, if we interpret the disclosure as earnings announcement, the non-linear relation between disclosure and price suggests that the earnings-price relation becomes non-linear after we incorporate the investment effect of disclosure. For example, the liquidation option (e.g., Hayn (1995)) may be interpreted as one particular type of the investment effect: upon the receipt of persistent bad news, the firm could liquidate itself (reverse its investment) to maximize the shareholder value. Future research may understand the non-linear earnings-price relation better by considering the investment effect of disclosure. Technically, previous literature relies heavily on the framework of CARA utility plus normally distributed wealth to solve for the closed-form expression of investors' welfare (their ex ante expected utility) that facilitates comparative statics. The Chi-square distribution of the trading price adds substantial challenges to this task. As a result, while I still manage to obtain the closed-form solution and some comparative statics, some structural beauty of the previous framework, such as expressing investors' welfare as a linear combination of the mean and variance of the firm's cash flow, inevitably gets lost.

\section{Disclosure Quality, Cost of Capital, and Investors' Welfare}

Having characterized the equilibrium, I conduct comparative statics in this section to addresses the main research questions. I first identify the necessary and sufficient conditions under which disclosure quality reduces cost of capital and improves the welfare of current and new investors. Then, I compare these conditions to show that they are not equivalent, nor do they subsume each other, as summarized in Table 2. Therefore, cost of capital does not summarize the impact of disclosure quality on the welfare of either current or new investors.

Insert Table 2 here.

\subsection{Disclosure Quality and Cost of Capital}

I define cost of capital as the expected return on the firm's equity.

$$
E[\tilde{R}]=\frac{E-P}{P}
$$

This definition is similar to that in Lambert, Leuz, and Verrecchia (2007) except that I use the unconditional expected return whereas they use the conditional expected return $E[\tilde{R} \mid y]$. Since we focus on the consequences of disclosure quality, it is important to eliminate the confounding effect of the realization of disclosure. Moreover, because the unconditional expected return $E[\tilde{R}]$ is the value weighted average of the 
conditional expected returns $E[\tilde{R} \mid y]$, it is the obtainable return for an investor who invests in the same firm over time or simultaneously in many similar firms. ${ }^{12}$ In addition, given the representation of information as a draw from a normal distribution, the conditional expected return could be negative. Besides its practical undesirability, the negative cost of capital also flips the sign of the impact of disclosure quality on cost of capital. The unconditional expected return circumvents this issue by averaging out the particular realizations of the signal $y$. As a result, the unconditional expected return is always positive under the following regularity condition 6 :

$$
\mu_{0}>\hat{\mu}_{0}=\frac{2 \alpha z m^{2}-\beta \tau_{n}}{4 \alpha m+2 \alpha^{2} z m \tau_{n}+2 \alpha \beta z m \tau_{n}}
$$

Note that $\hat{\mu}_{0}$ is independent of the signal $y$.

Proposition 1 (Disclosure Quality and Cost of Capital). As disclosure quality improves, cost of capital decreases if and only if the adjustment cost of new investment is sufficiently high $\left(z>z^{*}\right)$ or the prior expected profitability of the firm's existing investment is sufficiently low $\left(\mu_{0}<\mu_{0}^{*}\right)$.

The cutoff $z^{*}$ is the same as that in Lemma 2, and $\mu_{0}^{*}$ is given in expression A-18 in the appendix.

Proposition 1 extends the relation between disclosure quality and cost of capital to a production economy and confirms the conjecture in Lambert, Leuz, and Verrecchia (2007). ${ }^{13}$ The intuition behind Proposition 1 centers on the impacts of disclosure quality on the characteristics of the distribution of the firm's cash flow (Lemma 2). Cost of capital measures the per-dollar risk premium. The size of the overall risk premium increases with the variance of the firm's cash flow, and the scaling variable (i.e. the stock price) increases with the prior expected profitability of the firm's existing investment. Disclosure quality could increase cost of capital if it increases the variance and the variance grows faster than the stock price. A sufficiently low adjustment cost guarantees the increasing variance and a sufficiently high prior expected profitability further ensures that the per-dollar variance is increasing. This intuition is borne out by the following analysis. ${ }^{14}$

\footnotetext{
12$$
E[\tilde{R}]=\frac{E-P}{P}=\int_{-\infty}^{\infty} \frac{E[\tilde{F} \mid y]-p(y)}{p(y)} \frac{p(y)}{\int_{-\infty}^{\infty} p(y) \phi(y) d y} \phi(y) d y=\int_{-\infty}^{\infty} E[\tilde{R} \mid y] \frac{p(y)}{\int_{-\infty}^{\infty} p(y) \phi(y) d y} \phi(y) d y
$$

where $\phi(y)$ is the probability density function of $\tilde{y}$.

${ }^{13}$ See Proposition 4 in Lambert, Leuz, and Verrecchia (2007), page 410.

${ }^{14}$ Note that Proposition 1 is robust to different definitions of cost of capital. While Lambert, Leuz, and Verrecchia (2007) and my paper define cost of capital in the return space, Easley and O'Hara (2004) and Hughes, Liu, and Liu (2007) define it in the price space: $E[\tilde{R}]=E-P=\frac{V}{\tau_{n}}$. Disclosure quality influences cost of capital only through its impact on the variance of the firm's cash flow. Thus, Given Lemma 2, disclosure quality increases cost of capital in the price space if and only if the adjustment cost $z$ is sufficiently low.
} 
We can rewrite cost of capital as a function of the variance-mean ratio of the firm's cash flow by plugging equation 4 to equation 5.

$$
E[\tilde{R}]=\frac{1}{\frac{\tau_{n}}{\frac{V}{E}}-1}
$$

Cost of capital increases monotonically with the variance-mean ratio $\left(\frac{V}{E}\right)$ and decreases with new investors' risk tolerance $\left(\tau_{n}\right)$. Cost of capital increases with disclosure quality if and only if the sign of the following partial derivative is positive. The prime " $\prime$ " denotes the partial derivative with respect to $\beta$.

$$
\frac{\partial E[\tilde{R}]}{\partial \beta}=\frac{E E^{\prime} \tau_{n}}{\left(\tau_{n} E-V\right)^{2}}\left(\frac{V^{\prime}}{E^{\prime}}-\frac{V}{E}\right)
$$

When does $\frac{\partial E[\tilde{R}]}{\partial \beta}>0$ ? First, a positive $V^{\prime}$ is a necessary condition for the derivative to be positive. All variables in equation 8 are always positive except $V^{\prime} .{ }^{15}$ If $V^{\prime}<0$, then $\frac{V^{\prime}}{E^{\prime}}<0, \frac{\partial E[\tilde{R}]}{\partial \beta}<0$, and disclosure quality monotonically reduces cost of capital. By Lemma $2, V^{\prime}<0$ is equivalent to the condition that the adjustment cost of the firm's new investment is sufficiently high $\left(z>z^{*}\right)$. This explains the condition about the adjustment cost $z$ in Proposition 1.

Second, when $V^{\prime}>0$, the sign of the derivative is determined solely by the sign of the difference between two variance-mean ratios, $\frac{V^{\prime}}{E^{\prime}}-\frac{V}{E}$. The economic intuition of these two ratios is as follows. Consider a marginal increase in disclosure quality which causes an incremental change in the firm's cash flow. The firm's new cash flow becomes a weighted average of the pre-change cash flow with a variancemean ratio of $\frac{V}{E}$, and the incremental cash flow with a variance-mean ratio of $\frac{V^{\prime}}{E^{\prime}}$. If the variance-mean ratio of the incremental cash flow $\left(\frac{V^{\prime}}{E^{\prime}}\right)$ is greater than that of the pre-change cash flow $\left(\frac{V}{E}\right)$, the new (weighted average) variance-mean ratio becomes greater and cost of capital increases. ${ }^{16}$

Finally, how are the variance-mean ratios determined? Note that the prior expected profitability $\mu_{0}$ does not change the incremental cash flow, but affects the pre-change cash flow by altering the mean $E$. All else being equal, when $\mu_{0}$ is greater, $E$ is greater, and thus $\frac{V}{E}$ is smaller. When $\mu_{0}$ is great enough, $\frac{V^{\prime}}{E^{\prime}}$ exceeds $\frac{V}{E}$ and $\frac{\partial E[\tilde{R}]}{\partial \beta}>0$. This completes the intuition of Proposition 1. Further, the intuition that disclosure quality influences cost of capital through its impact on the variance-mean ratio of the firm's cash flow becomes more transparent in three special economies.

\footnotetext{
${ }^{15}$ Recall that under condition 6 , the price $P$ is positive. Since the variance $V$ is positive, $E=P+\frac{1}{\tau_{n}} V$ is also positive. Finally, Lemma 2 proves that $E^{\prime}$ is positive.

${ }^{16}$ Another interpretation of the result is to rewrite equation 8 as $\frac{\partial E[\tilde{R}]}{\partial \beta}=\frac{E V \tau_{n}}{\left(\tau_{n} E-V\right)^{2}}\left(\frac{V^{\prime}}{V}-\frac{E^{\prime}}{E}\right)$. The impact of disclosure quality on cost of capital is determined by the disclosure quality elasticity of variance and mean.
} 
Corollary 1 (Disclosure Quality and Cost of Capital in the Special Economies). As disclosure quality improves, cost of capital decreases in the pure exchange economy and in the economy without existing investment, but increases in the CRTS economy.

In the pure exchange economy, the variance-mean ratio is $\left(\frac{V}{E}\right)_{p e}=\lim _{z \rightarrow \infty, m \rightarrow 1} \frac{V}{E}=\frac{\operatorname{Var}[\tilde{\mu} \mid y]}{\mu_{0}}$. Disclosure quality monotonically reduces $\operatorname{Var}[\tilde{\mu} \mid y]$ and thus reduces cost of capital. Disclosure quality does not change the mean but always reduces the conditional variance of the firm's cash flow, resulting in a decreasing variance-mean ratio.

When the investment effect is present, disclosure quality affects both the mean and variance of the firm's cash flow. As a result, the impact of disclosure quality on cost of capital becomes more subtle. In the economy without existing investment, the variance-mean ratio is $\left(\frac{V}{E}\right)_{w e}=\lim _{m \rightarrow 0} \frac{V}{E}=\frac{2 \tau_{n}}{4+\frac{z \tau_{n}}{\operatorname{Var}[\tilde{\mu} \mid y]}}$. Disclosure quality also monotonically reduces $\operatorname{Var}[\tilde{\mu} \mid y]$ and thus reduces cost of capital. In this economy, the mean of the firm's cash flow monotonically increases with disclosure quality, while the variance has a one-peak shape. The mean turns out to grow faster than the variance. As a result, disclosure quality also decreases the variance-mean ratio. ${ }^{17}$

The CRTS economy provides an example in which the variance outpaces the mean. In this economy, the variance-mean ratio is $\left(\frac{V}{E}\right)_{c r t s}=\lim _{z \rightarrow 0} \frac{V}{E}=\frac{\tau_{n}}{2+\frac{m \mu_{0} \tau_{n}}{V_{c r t s}}}$. Disclosure quality monotonically increases $V_{c r t s}$ and thus increases cost of capital. As disclosure quality improves, both the mean and variance increase, but the variance grows faster than the mean, leading to an increasing variance-mean ratio.

In sum, disclosure quality affects cost of capital through its impact on the variance-mean ratio of the firm's cash flow. In the presence of the investment effect, disclosure quality affects both the mean and variance of the firm's cash flow. As a result, there are plausible conditions under which disclosure quality increases cost of capital.

\subsection{Disclosure Quality and Current Investors' Welfare}

In this subsection, I analyze how disclosure quality affects current investors' welfare and identify the necessary and sufficient conditions under which disclosure quality improves current investors' welfare. By comparing the impacts of disclosure quality on cost of capital and on current investors' welfare, I demonstrate that cost of capital is not a sufficient statistic for current investors' welfare. The third column in Table 2 summarizes the results in this subsection.

\footnotetext{
${ }^{17}$ Lambert, Leuz, and Verrecchia (2007) analyze a similar example of the production economy without existing investment.
} 
I define investors' welfare as their ex ante expected utility: the utility after the disclosure quality has been set, but before the signal comes out. In particular, current investors' welfare is as follows:

$$
E\left[U\left(W_{c}\right)\right]=E\left[E\left[U\left(W_{c}\right) \mid y\right]\right]=M_{1} \exp \left(M_{2}\right)
$$

where $M_{1}$ and $M_{2}$ are given in expressions (A-21) and (A-22) in the appendix. The complexity of $M_{1}$ and $M_{2}$ results from the investment effect, which induces a Chi-square distribution of $p(y)$. As a result, the convenient framework of CARA utility plus normally distributed wealth is not applicable to the calculation of the welfare. Instead, the calculation involves Lemma 5 which is given and proved in the appendix.

Proposition 2 (Disclosure Quality and Current Investors' Welfare). As disclosure quality improves, current investors are better off if and only if they are sufficiently risk tolerant relative to new investors $\left(\tau_{c}>\frac{\tau_{n}}{2}\right)$ or the adjustment cost of new investment is sufficiently low $\left(z<z_{c}^{*}\right)$.

The cutoff $z_{c}^{*}$ is characterized in expression (A-23) in the appendix.

Besides extending the results in Dye (1990) by studying the welfare impact of disclosure quality in a production economy, Proposition 2, together with Proposition 1, reveals that the conditions for disclosure quality to reduce cost of capital and to improve current investors' welfare are different and do not subsume each other, as summarized in Remark 1.

Remark 1 (Cost of Capital and Current Investors' Welfare). In the analysis of the economic consequences of disclosure quality, cost of capital is not a sufficient statistic for current investors' welfare.

The intuition for Proposition 2 lies in the dual effect of disclosure quality of facilitating investment and allocating risk. On one hand, disclosure coordinates the firm's investment decisions better with the market's expectations, which enhances current investors' welfare. On the other hand, disclosure quality also allocates the risk between current and new investors by resolving the uncertainty before current investors transfer it to new investors. Whether this risk allocation effect improves current investors' welfare or not depends on the relative risk tolerance of current and new investors. When current investors are sufficiently risk averse and the improvement in investment is marginal, disclosure quality could reduce current investors' welfare.

The special economies provide transparent intuition for Proposition 2 and Remark 1. The pure exchange economy illustrates the welfare consequences of the risk allocation effect; the economy without existing investment demonstrates the welfare impact of the investment effect; and all three special economies are informative about the discrepancy between cost of capital and current investors' welfare in Remark 1. 
Corollary 2 (Disclosure Quality and Current Investors' Welfare in the Special Economies). As disclosure quality improves, current investors are better off in the pure exchange economy if and only if they are sufficiently risk tolerant $\left(\tau_{c}>\frac{\tau_{n}}{2}\right)$, and they are always better off in both the economy without existing investment and the CRTS economy.

In the pure exchange economy, disclosure divides the firm's risk into the price risk and the cash flow risk. Disclosure quality reduces the cash flow risk but increases the price risk, creating a trade-off for current investors' welfare. Formally, the certainty equivalent of the welfare of current investors is as follows:

$$
\begin{aligned}
\left(C E_{c}\right)_{p e} & =P-\frac{1}{2 \tau_{c}} \operatorname{Var}[p(y)] \\
& =\mu_{0}-\frac{1}{\tau_{n}} \underbrace{\operatorname{Var}[\tilde{\mu} \mid y]}_{\text {Cash Flow Risk }}-\frac{1}{2 \tau_{c}} \underbrace{\operatorname{Var}[E[\tilde{\mu} \mid y]]}_{\text {Price Risk }} \\
& =\mu_{0}-\frac{1}{2 \tau_{c}} \frac{1}{\alpha}+\left(\frac{1}{2 \tau_{c}}-\frac{1}{\tau_{n}}\right) \operatorname{Var}[\tilde{\mu} \mid y]
\end{aligned}
$$

Equation 10 indicates that current investors care about not only the average level but also the ex ante uncertainty of their ex post wealth $p(y)$. Equation 11 shows that current investors suffer from both the cash flow risk and the price risk, which constitute the initial risk of the firm's cash flow $(\operatorname{Var}[\tilde{\mu}])$. Disclosure quality substitutes the price risk for the cash flow risk. Equation 12 reveals the trade-off for current investors. Loosely speaking, one more unit of the price risk costs current investors a relative disutility of $\frac{1}{2 \tau_{c}}$ utile, and one more unit of the cash flow risk costs them $\frac{1}{\tau_{n}}$ utile. Thus, the reduction in the cash flow risk improves current investors welfare if and only if $\frac{1}{2 \tau_{c}}-\frac{1}{\tau_{n}}<0$, which is equivalent to $\tau_{c}>\frac{\tau_{n}}{2}$. When it is relatively more expensive to bear the risk by themselves, current investors would rather pay new investors to take the risk for them. In this case, by resolving uncertainty before trading, disclosure quality prevents current investors from "outsourcing" more risk to new investors and makes current investors worse off.

Having analyzed how disclosure quality affects current investors' welfare in the pure exchange economy, now I discuss the intuition behind Remark 1 that cost of capital is an incomplete measure of current investors' welfare. On one hand, this observation seems to be intuitive. From the perspective of current investors, cost of capital measures the cost they pay new investors to bear the risk for them. When they are sufficiently more risk averse than new investors, saving the cost of "outsourcing" the risk reduces, not improves, their welfare. On the other hand, conventional wisdom conjectures that lower cost of capital increases the present value of a given distribution of cash flow, resulting in higher welfare for current investors. I formally show that the conventional wisdom is only a partial equilibrium observation. In the pure exchange economy, cost of capital measures only the average level of current investors' ex post wealth, but does not capture the ex ante 
uncertainty of their wealth. Disclosure quality affects both cost of capital and the ex ante uncertainty of their wealth simultaneously, making cost of capital an incomplete measure of the impact of disclosure quality on current investors' welfare. We could rewrite current investors' certainty equivalent as three components:

$$
\left(C E_{c}\right)_{p e}=\mu_{0}-\frac{E[\tilde{R}]}{1+E[\tilde{R}]} \mu_{0}-\frac{1}{2 \tau_{c}} \operatorname{Var}[E[\tilde{\mu} \mid y]]
$$

The first component is the expected value of the firm's cash flow, the second component is the risk discount current investors concede to new investors, and the last is their utility loss from the price risk. The conventional wisdom is applicable to the case where the price risk is held constant while cost of capital is decreasing. For example, according to equation 7 , an increase in new investors' risk tolerance $\left(\tau_{n}\right)$ reduces cost of capital $E[\tilde{R}]$ (the second component), but keeps the price risk $\operatorname{Var}[E[\tilde{\mu} \mid y]]$ (the third component) unchanged. As a result, the decrease in cost of capital in this case does improve the welfare of current investors by reducing the risk premium new investors require.

However, in the analysis of the economic consequences of disclosure quality, the conventional wisdom is flawed. Disclosure quality reduces cost of capital by substituting the price risk for the cash flow risk. By expediting the resolution of uncertainty, disclosure quality simultaneously affects cost of capital and the price risk. Lower cost of capital does reduce the risk premium current investors pay to new investors (the second component in equation 13), but the benefit comes at the cost of more exposure to the price risk (the third component in equation 13). When current investors are sufficiently risk averse, the saving in risk premium can not compensate for their disutility from the increased exposure to the price risk. As a result, they are worse off although cost of capital decreases. Therefore, cost of capital is not a comprehensive measure of current investors' welfare.

The other two special economies illustrate the welfare impact of the investment effect. Furthermore, they demonstrate that cost of capital is not a comprehensive measure of even current investors' level of wealth after controlling for its ex ante uncertainty.

In the economy without existing investment, there is no risk before disclosure, and thus the risk allocation effect is muted. Current investors' welfare is $\left(E\left[U\left(W_{c}\right)\right]\right)_{w e}=\lim _{m \rightarrow 0} E\left[U\left(W_{c}\right)\right]=-\frac{1}{\sqrt{1+\frac{2}{\tau_{c}} P_{w e}}}$. Disclosure quality affects current investors' welfare only through its impact on the level of their wealth and the ex ante uncertainty of their wealth does not play a role. ${ }^{18}$ Since disclosure quality monotonically increases the stock price, the investment effect enhances current investors' welfare. Furthermore, cost of

\footnotetext{
${ }^{18} \mathrm{~A}$ non-central Chi-square distribution is completely characterized by the number of degrees of freedom and the location parameter. Since the mean contains both parameters, it is possible that the mean could happen to capture other higher order moments.
} 
capital is not a comprehensive measure of the impact of disclosure quality on the level of current investors' wealth. Since $P=\frac{E}{1+E[\tilde{R}]}$, disclosure quality improves the mean and reduces cost of capital at the same time. Therefore, cost of capital is not the only channel for disclosure quality to influence current investors' welfare. This observation substantiates Remark 1.

In the CRTS economy, the risk allocation is also absent because the firm could always undo the existing investment: $k(y)=-m+\frac{\tau_{n}}{2} \frac{E[\tilde{\mu} \mid y]}{\operatorname{Var}[\tilde{\mu} \mid y]}$. Current investors' welfare is $\left(E\left[U\left(W_{c}\right)\right]\right)_{c r t s}=\lim _{z \rightarrow 0} E\left[U\left(W_{c}\right)\right]=$ $-\frac{\exp \left(-\frac{m \mu_{0}}{\tau_{c}}\right)}{\sqrt{1+\frac{2\left(P_{c r t s}-m \mu_{0}\right)}{\tau_{c}}}}$. Therefore, current investors only care about the level of their wealth $P$, implying that current investors benefit from better disclosure. Moreover, Remark 1 is more evident in the CRTS economy because both cost of capital and current investors' welfare increase with disclosure quality. While disclosure quality increases cost of capital, it also improves the mean of the firm's cash flow. The welfare gain from the increased mean dominates the welfare loss from the increased cost of capital, leading to the overall improved welfare for current investors.

In sum, cost of capital is not a sufficient statistic for current investors' welfare in the analysis of the economic consequences of disclosure quality. Current investors care about both the level and the ex ante uncertainty of their wealth. Cost of capital does not capture the ex ante uncertainty and is only associated with one component of the level of current investors' wealth. ${ }^{19}$ Disclosure quality changes cost of capital and other components of current investors' welfare simultaneously.

\subsection{Disclosure Quality and New Investors' Welfare}

Having examined the impact of disclosure quality on current investors' welfare and the discrepancy between cost of capital and current investors' welfare, I analyze the welfare impact of disclosure quality on new investors in this subsection and identify the necessary and sufficient conditions for disclosure quality to improve new investors' welfare. By comparing the impacts of disclosure quality on cost of capital and on new investors' welfare, I demonstrate that cost of capital is not a sufficient statistic for new investors' welfare, either. In addition, I show that disclosure quality creates a tension between current and new investors. The last column of Table 2 summarizes the results of this subsection.

\footnotetext{
${ }^{19}$ The discrepancy between current investors' welfare and cost of capital is partially attributable to the fact that welfare is defined ex ante while cost of capital is derived from prices traded after disclosure, highlighting the limitation of the concept of cost of capital used in the literature. Nonetheless, Christensen, De La Rosa, and Feltham (2008) demonstrate that even ex ante cost of capital does not measure welfare.
} 
Similarly, the welfare of new investors is their ex ante expected utility.

$$
E\left[U\left(W_{n}\right)\right]=-E\left[E\left[U\left(W_{n}\right) \mid y\right]\right]=-E\left[\exp \left(-\frac{1}{2 \tau_{n}^{2}} \operatorname{Var}[\tilde{F} \mid y]\right)\right]=N_{1} \exp \left(N_{2}\right)
$$

where $N_{1}$ and $N_{2}$ are given in expressions (A-27) and (A-28) in the appendix. Again, the calculation of the ex ante expected utility involves Lemma 5 , resulting in the complexity of $N_{1}$ and $N_{2}$.

Proposition 3 (Disclosure Quality and New Investors' Welfare ). As disclosure quality improves, new investors are better off if and only if one of the following two conditions holds:

1. If the initial disclosure quality is low $(\beta<\alpha)$, then either the adjustment cost of new investment is sufficiently low $\left(z<z_{n}^{*}\right)$, or the level of existing investment is sufficiently low $\left(m<m_{n}^{*}\right)$;

2. If the initial disclosure quality is high $(\beta>\alpha)$, then either the adjustment cost of new investment is sufficiently low $\left(z<z_{n}^{*}\right)$, or the adjustment cost of new investment is modest (i.e., $z_{n}^{*}<z<z_{n}^{* *}$ ) and the level of existing investment is sufficiently low $\left(m<m_{n}^{*}\right)$.

Proposition 3 is also illustrated in Figure 4. Disclosure quality increases new investors' welfare in the grid areas. The cut-offs, $z_{n}^{*}, z_{n}^{* *}$, and $m_{n}^{*}$, are given in expressions A-29, A-30, and A-31 in the appendix.

$$
\beta<\alpha
$$

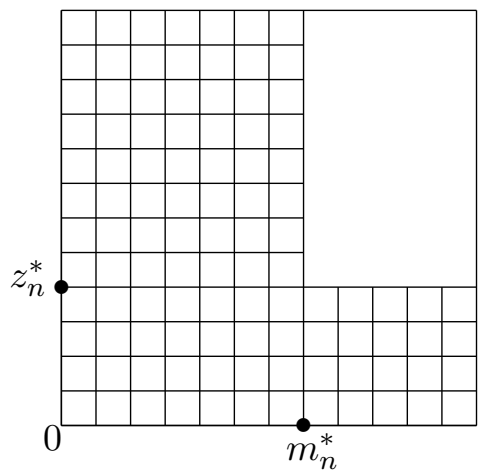

$$
\beta>\alpha
$$

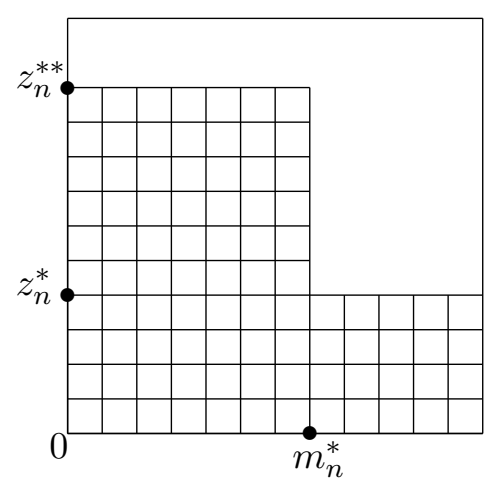

Figure 4 : The Impact of Disclosure Quality on New Investors' Welfare

Besides stipulating the necessary and sufficient conditions under which new investors are better off with better disclosure, Proposition 3 indicates that disclosure quality influences the welfare of new investors in different ways than it affects cost of capital, as summarized in Remark 2. In addition, the comparison between Proposition 2 and Proposition 3 reveals that current and new investors have conflicting demands for disclosure quality, as represented in Remark 3. 
Remark 2 (Cost of Capital and New Investors' Welfare). In the analysis of the economic consequences of disclosure quality, cost of capital is not a sufficient statistic for new investors' welfare.

Remark 3 (The Tension between Current and New Investors). Current and new investors could have conflicting demands for disclosure quality.

There are two elements in the intuition behind Proposition 2. First, new investors' conditional expected utility increases with the cash flow risk $(\operatorname{Var}[\tilde{F} \mid y])$. Second, they are averse to the ex ante uncertainty of their conditional expected utility.

The first element may seem surprising, although it is evident in equation 14 that $E\left[U\left(W_{n}\right)\right]$ increases with $\operatorname{Var}[\tilde{F} \mid y]$. Not only do new investors gain positive surplus from trading in a competitive market, but also the size of the surplus increases with the cash flow risk they take. The following analysis reveals that the source of new investors' trading surplus is their risk aversion. Further, the cash flow risk increases their surplus because it makes their demand less price sensitive and reduces competition among themselves.

Since new investors are risk averse, their demand (D) is downward-sloping, as shown in the appendix (equation A-3):

$$
D=\tau_{n} \frac{E[\tilde{F} \mid y]-p(y)}{\operatorname{Var}[\tilde{F} \mid y]}
$$

The downward-sloping demand curve yields diminishing marginal utility (MU $\left.=E[\tilde{F} \mid y]-\frac{\operatorname{Var}[\tilde{F} \mid y]}{\tau_{n}} D\right)$, which in turn determines the price $(p(y))$ in equilibrium. As a result, the price is lower than the average utility $\left(\mathrm{AU}=E[\tilde{F} \mid y]-\frac{\operatorname{Var}[\tilde{F} \mid y]}{2 \tau_{n}} D\right)$. The gap between MU and AU, $\frac{\operatorname{Var}[\tilde{F} \mid y]}{2 \tau_{n}}$, is the source of new investors' surplus from trading in a competitive market. In contrast, when new investors become risk neutral in the limit, the gap between MU and AU disappears and $p(y)=E[\tilde{F} \mid y]$. As a result, new investors always pay a "fair" price for whatever they get, consistent with the notion that trading is a fair game for risk-neutral investors in a competitive market. New investors' welfare is not directly affected by whatever impacts disclosure has on the mean of the future cash flow $(E)$ because the adjustment of the price absorbs such impacts.

Competition among new investors does affect and reduce the surplus they gain from trading, but in a subtle way. When the cash flow risk $(\operatorname{Var}[\tilde{F} \mid y])$ is higher, new investors' demand for the firm's shares in equation 15 becomes less sensitive to price. That is, the slope of their demand curve $\left(-\frac{\operatorname{Var}[\tilde{F} \mid y]}{\tau_{n}}\right)$ becomes much steeper. Less sensitive demands amount to less competition among themselves, increasing the gap between $\mathrm{MU}$ and $\mathrm{AU}$ and thus their surplus. 
The forced nature of current investors' sale increases, but does not generate, new investors' surplus. When current investors have to leave the market after disclosure, the total risk-taking capacity in the market shrinks, reducing the overall competition for the firm's risky shares and improving the reward for risk-taking by new investors. However, even if current investors stay in the market, new investors still gain surplus from trading, although both the gap between MU and AU and their equilibrium holding become smaller, leading to lower surplus for them.

Second, new investors' welfare is the (probability) weighted average of their conditional expected utility. Since they are risk averse, new investors are averse to the ex ante uncertainty of their conditional expected utility. From the perspective of new investors before disclosure, one realization of $y$ leads to one conditional distribution of the firm's cash flow $(\tilde{F} \mid y)$ with differential mean and variance. Thus, disclosure creates ex ante uncertainty of the conditional cash flow risk $(\operatorname{Var}[\tilde{F} \mid y])$ and the ex ante uncertainty of new investors' conditional expected utility.

Overall, disclosure quality improves new investors' welfare if and only if it increases the conditional variance of the firm's cash flow and the increase is large enough to offset their welfare loss from the increased ex ante uncertainty of the conditional expected utility. The special economies make the intuition more transparent and illustrate Remark 2 and 3.

Corollary 3 (Disclosure Quality and New Investors' Welfare in the Special Economies). As disclosure quality improves, new investors are always worse off in the pure exchange economy, always better off in the CRTS economy, and better off in the economy without existing investment if and only if the adjustment cost of new investment is sufficiently low $\left(z<\frac{2}{(\beta-\alpha) \tau_{n}}\right)$.

In the pure exchange economy, new investors' welfare is $\left(E\left[U\left(W_{n}\right)\right]\right)_{p e}=\lim _{z \rightarrow \infty, m \rightarrow 1} E\left[U\left(W_{n}\right)\right]=$ $-\exp \left(-\frac{1}{2 t_{n}^{2}} \operatorname{Var}[\tilde{\mu} \mid y]\right)$. Disclosure quality decreases new investors' welfare by leaving less risk for them to take through trading. Moreover, cost of capital does not link disclosure quality to new investors' welfare, either. High disclosure quality reduces cost of capital by materializing more risk before trading, but this early resolution of uncertainty reduces the demand for new investors' risk tolerance and thus reduces their welfare. Therefore, cost of capital is a comprehensive measure of the welfare of neither current nor new investors. Finally, Remark 3 is also evident in the pure exchange economy. While current investors' preference for disclosure quality depends on their relative risk tolerance, new investors always prefer lower disclosure quality.

In the economy without existing investment, new investors' welfare is $\left(E\left[U\left(W_{n}\right)\right]\right)_{w e}=\lim _{m \rightarrow 0} E\left[U\left(W_{n}\right)\right]=$ 
$-\frac{1}{\sqrt{1+\frac{1}{\tau_{n}^{2}} V_{w e}}}$. New investors' welfare increases monotonically with the variance of the firm's cash flow. Since the variance of the firm's cash flow has a one-peak shape, new investors benefit from better disclosure quality when the variance is increasing, that is, when $z<\frac{2}{(\beta-\alpha) \tau_{n}}$, according to Lemma 3. Moreover, this economy provides another example of the discrepancy between cost of capital and new investors' welfare. Driven by the decreasing variance-mean ratio, cost of capital decreases with disclosure quality. In contrast, new investors' welfare is driven by the variance alone, and thus could either increase or decrease with disclosure quality. Finally, this economy also lends support to Remark 3. When $z>\frac{2}{(\beta-\alpha) \tau_{n}}$, current investors advocate more transparency while new investors prefer less.

In the CRTS economy, new investors' welfare is $\left(E\left[U\left(W_{n}\right)\right]\right)_{\text {crts }}=\lim _{z \rightarrow 0} E\left[U\left(W_{n}\right)\right]=-\frac{1}{\sqrt{1+\frac{1}{\tau_{n}^{2}} V_{\text {crts }}}}$. New investors' welfare increases with the variance of the firm's cash flow, which increases with disclosure quality in the CRTS economy. Thus, they are better off with better disclosure quality. Moreover, Remark 2 is striking in the CRTS economy. New investors' welfare increases with disclosure quality. So does cost of capital! We can rewrite new investors' welfare as a function of cost of capital: $\left(E\left[U\left(W_{n}\right)\right]\right)_{\text {crts }}=$ $-\frac{1}{\sqrt{1+\frac{m \mu_{0}}{\tau_{n}} \frac{E[\tilde{R}]}{1-E[\tilde{R}]}}}$. Since $E[\tilde{R}] \in(0,1)$, current investors' welfare increases with cost of capital. Disclosure quality increases both the mean and variance of the firm's cash flow, but the variance outpaces the mean. As a result, as disclosure quality improves, cost of capital increases because of the increasing variance-mean ratio, and new investors' welfare also increases because of the increasing variance. Thus, disclosure quality does not summarize the impact of disclosure quality on new investors' welfare. Finally, although disclosure quality increases the welfare of both current and new investors, it does so through different channels. Current investors benefit from the improved mean of the firm's cash flow but suffer from the accompanying increase in the variance, whereas new investors enjoy only the increase in the variance.

In all three special economies, new investors' preference for disclosure quality could be summarized by the impact of disclosure quality on the the average level of their conditional expected utility (or the variance of the firm's cash flow $V$ ). When the risk allocation effect interacts with the investment effect, the ex ante uncertainty of the cash flow risk $(\operatorname{Var}[\tilde{F} \mid y])$ also plays a role in new investors' welfare. This interaction leads to the difference between the conditions in Proposition 3 about the impact of disclosure quality on new investors' welfare and the conditions in Lemma 2 about the impact of disclosure quality on the variance of the firm's cash flow.

In sum, cost of capital is not a sufficient statistic for new investors' welfare, either. New investors earn surplus from risk-bearing in equilibrium. Their welfare is determined by both the average level and the ex 
ante uncertainty of the amount of the cash flow risk they could take from trading, and cost of capital is only partially associated with the first component.

\section{Empirical Implications}

The results have a number of empirical implications for the relation between disclosure quality and cost of capital, the economic consequences of disclosure quality in general, and the evaluations of disclosure regulation and financial reporting standards.

The empirical literature often cites Levitt (1998) as the motivation for examining the relation between disclosure quality and cost of capital, and Easley and O'Hara (2004) as the theoretical foundation of the empirical hypothesis that disclosure quality reduces cost of capital by leveling "the playground" among investors. Lambert, Leuz, and Verrecchia (2006) demonstrate that, in Easley and O'Hara (2004), disclosure quality reduces cost of capital by increasing the average information precision, not by reducing information asymmetry per se. This study further shows that the implicit assumption about the monotonic link between cost of capital and investors' welfare is not well justified. This raises a question about how we should interpret and use the empirical evidence on the relation between disclosure quality and cost of capital in the public debate about disclosure regulation and financial reporting standards.

In terms of the relation between disclosure quality and cost of capital, the results in this study suggest that the impact of disclosure quality on cost of capital crucially depends on the intensity of the investment effect. Lambert, Leuz, and Verrecchia (2007) caution that cross-sectional studies in this area may only capture the "average" impact of the investment effect; this paper further identifies one intermediate variable, the adjustment cost of new investment, to help sort out the directional effects of disclosure quality on cost of capital. If we include proxies for the adjustment cost of new investment in the previous regressions, we may reconcile the mixed empirical evidence.

The model is agnostic about whether information risk is a systematic risk factor over and above traditional risk factors. To some extent, identifying a risk factor beyond CAPM beta is a purely empirical issue, and information risk is no exception. One common theme in the theoretical literature is that the impact of disclosure quality could be summarized by its impact on the traditional variance (or covariance) of the firm's cash flow (or with the cash flow of the market portfolio). Given that the literature starts with the framework of CAPM or APT, it is difficult to use this framework to prove or disprove an additional risk factor. In addition, while my model predicts how disclosure quality affects cost of capital, it is silent on the issue that 
through which component(s), the factor premium or/and the factor loading, disclosure quality affects cost of capital. The answer to this issue depends on whether we measure cost of capital in the return space or in the price space, as demonstrated in Hughes, Liu, and Liu (2007) and Lambert, Leuz, and Verrecchia (2007).

As a result, a more direct test of my theory about the economic consequences of disclosure is to examine how changes in disclosure quality influence the distribution of the firm's cash flow and whether such influence cross-sectionally varies with the firm's adjustment cost of new investment. Similarly, the theory predicts that firms, whose investment decisions could be improved substantially by disclosure quality and whose current owners have strong risk-taking capacity, are more likely to choose high disclosure quality. For example, it may explain that why some firms choose public financing or cross-listing while other remain private or listed domestically. In addition, it also predicts that exchanges with differential disclosure requirements have distinct clienteles who vary in their flexibility of new investment.

Finally, the empirical testing of the investment effect could be a promising direction. While there are a number of theoretical channels through which disclosure quality could influence the firm's investment decisions, empirically we still know little about them. Verdi (2006) and Hope and Thomas (2008) provides empirical evidence on the possible mechanisms through which disclosure quality affects a firm's investment efficiency. Further understanding of the empirical determinants of the investment effect will provide better inputs to the empirical examination of the relation between disclosure quality and cost of capital, as well as other predictions of this paper.

\section{Extensions}

So far, I have used a simplistic model to make my arguments. This subsection discusses several possible extensions and generalizations to the model and their impacts on the results.

\subsection{Diversification}

Although I only study a single-firm economy, the analysis is robust to diversification in a multi-firm economy, thanks to Lambert, Leuz, and Verrecchia (2007). We can interpret the variance of the firm's cash flow used in this study as the covariance of the firm's cash flow with the cash flow of the market portfolio. The Bayes update rule for covariance is similar to that for variance, and thus the major proofs can go through with covariance. Therefore, focusing on a single-firm economy is without loss of generality. 


\subsection{Information Asymmetry}

There could be three types of information asymmetry: information asymmetry between the firm's manager and current investors, between current and new investors, and among new investors.

This paper assumes that the manager of the firm makes investment decisions to maximize current investors' interest. In other words, it is an entrepreneur-owner running firm. I do not explicitly model how the manager of the firm is motivated to act on (current) investors' interest, which has been the focus of many studies in the agency literature (e.g., Dye (1988)). Conceptually, the driving force in my model is that disclosure quality affects both the ex ante mean and variance of the firm's cash flow. In general, studies in agency theory show that disclosure quality changes the characteristics of the distribution of the firm's cash flow through its impact on the principal-agent relation (e.g., Lambert (2001)). Therefore, although incorporating the agency issue in the model may generate a different cash flow function, the main conclusion about the relation between cost of capital and investors' welfare is expected to be preserved.

Secondly, I have assumed that the firm does not have private information beyond what is disclosed. In an overlapping generation model, this assumption is innocuous. Even if the firm does have private information beyond the disclosure, the firm could not credibly convey it to new investors. In other words, there are no mechanisms for the firm to signal its private information and for new investors to screen firms.

One way to model the firm's private information is as follows. The disclosure is a garbling or subset of the information the firm has. Imagine that both $\gamma$ and $\beta$ are integers. The firm installs an information technology which generates $\gamma$ unbiased signals with unit precision, but is only required to disclose or commits to disclosing the first $\beta$ signals. $\tilde{y}$ is a sufficient statistic for these $\beta$ signals and a garbling of the $\gamma$ signals.

Even in this specification, the equilibrium in Lemma 1 is unique and there is no signaling equilibrium. To show the uniqueness of the equilibrium, we note that had new investors tried to extract information from $k(y)$, the firm would have pretended to be a better type than it actually is by opportunistically distorting its investment decisions. Since the firm maximizes its expected stock price that occurs right after disclosure and does not bear private cost for the distortion in investment, there is no disciplinary cost to discourage such opportunism. Therefore, the equilibrium in which new investors do not extract information from the investment and the firm does not use investment to send a signal is the only equilibrium. ${ }^{20}$ In other words,

\footnotetext{
${ }^{20}$ Kanodia and Lee (1998) and Kanodia, Singh, and Spero (2005) study signaling games in which the firm could convey information through its investment choice. In Kanodia and Lee (1998), the uncompromisable performance report, which occurs after the firm's investment decisions but before the trading, imposes differential cost on different types of firms. In Kanodia, Singh, and Spero (2005), the cost of distorted investment, the reduction in the private short-term value of the investment, is higher for the firm's
} 
even if we assume that the firm has private information beyond the disclosure, in equilibrium, the firm only uses its information to the extent that it is disclosed and priced by the market and new investors use only the disclosure to update their beliefs about $\tilde{\mu}$. Given that the paper focuses on the impact of disclosure quality on cost of capital and investors' welfare, this modeling choice of avoiding signaling equilibrium captures the essence of the investment effect while keeping the model tractable.

Finally, Easley and O'Hara (2004) address the question of how accounting disclosure "levels the playground" among asymmetrically informed new investors. However, Lambert, Leuz, and Verrecchia (2006) show that in a market with perfect competition, what affects cost of capital is investors' average information precision, not the degree of information asymmetry among investors per se. Since I adopt the perfect competition framework, the abstraction from the information asymmetry among new investors does not incur any loss of generality.

\subsection{Pre-disclosure Trading}

This paper focuses on the post-disclosure trading. I do not study the pre-disclosure trading and its preemptive effect on the impact of disclosure quality in capital market. As discussed in the setup of the model, trading is exogenous to this as well as many other models that study the consequences of accounting disclosure in capital market, due to the "no-trading" theorem. Replacing the forced sale assumption with probabilistic liquidity-driven sale should not qualitatively affect my results. ${ }^{21}$

Given the forced sale assumption, liquidity-based pre- and post-disclosure tradings are independent of each other, and thus the results in this paper about the post-disclosure trading will not be altered by the inclusion of the possible pre-disclosure trading. In addition, empirically, we observe significant abnormal trading volume after both scheduled and unscheduled corporate announcements (e.g., Chae (2005)), showing the relevance of the post-disclosure trading in reality.

In addition, the pre-disclosure trading captures the price that occurs after the disclosure quality is set but before the disclosure is made. In a different model, Christensen, De La Rosa, and Feltham (2008) show that ex ante cost of capital may not be affected by disclosure quality, complimenting to my results. Empirically, it corresponds to an event study where we test the market reaction right after the disclosure quality is changed. In contrast, the post-disclosure trading yields the price that prevails after the disclosure comes out and thus

with unfavorable information. In contrast, the absence of such differential cost in my model precludes any signaling equilibrium.

${ }^{21}$ If we allow the combination of current investors' partial selling and firm's private information, signaling equilibrium becomes possible. 
corresponds to an association study. Since it is usually difficult to determine the exact time news about changes in disclosure quality arrives in the market, the association study is currently popular in this area.

\section{Conclusion}

This paper scrutinizes the popular wisdom that disclosure quality improves investors' welfare by reducing cost of capital. In particular, I study the impacts of disclosure quality on cost of capital, current investors' welfare, and new investors' welfare in a production economy in which disclosure changes a firm's investment decisions. I identify the necessary and sufficient conditions under which disclosure quality reduces cost of capital and improves the welfare of current and new investors. Cost of capital could increase with disclosure quality and there are plausible conditions under which disclosure reduces the welfare of current and new investors. Then, I show that these conditions are not equivalent, nor do they subsume each other. Therefore, cost of capital does not summarize the impact of disclosure quality on the welfare of either current or new investors. In addition, disclosure quality also creates a tension between current and new investors.

With the caveat that they are derived from the particular model of perfect competition and overlapping generations of investors, these results may help reconcile the mixed empirical evidence on the relation between disclosure quality and cost of capital, inform the empirical efforts to measure the economic consequences of accounting disclosure, and add to the ongoing debate on the reform of financial reporting and disclosure regulation.

\section{References}

Arya, A., J. Glover, and S. Sunder, 1998, Earnings Management and the Revelation Principle, Review of Accounting Studies 3, 7-34.

_ 2003, Are Unmanaged Earnings Always Better for Shareholders?, Accounting Horizons 17, 111117.

Aumann, R.J., 1976, Agreeing to Disagree, The Annals of Statistics 4, 1236-1239.

Baiman, S., and R.E. Verrecchia, 1996, The Relation Among Capital Markets, Financial Disclosure, Production Efficiency, and Insider Trading, Journal of Accounting Research 34, 1-22. 
Brennan, M.J., and E.S. Schwartz, 1982, Consistent Regulatory Policy under Uncertainty, The Bell Journal of Economics 13, 506-521.

Chae, J., 2005, Trading Volume, Information Asymmetry, and Timing Information, The Journal of Finance $60,413-442$.

Christensen, P.O., Leonidas E. De La Rosa, and G.A. Feltham, 2008, Information and the Cost of Capital: An Ex-Ante Perspective, SSRN eLibrary.

Christensen, P.O., and G.A. Feltham, 1988, Firm-Specific Information and Efficient Resource Allocation, Contemporary Accounting Research 5, 133-169.

Diamond, D.W., 1985, Optimal Release of Information By Firms, The Journal of Finance 40, 1071-1094.

— , and R.E. Verrecchia, 1981, Information Aggregation in a Noisy Rational Expectations Economy, Journal of Financial Economics 9, 221-235.

— 1991, Disclosure, Liquidity, and the Cost of Capital, The Journal of Finance 46, 1325-1359.

Dow, J., and R. Rahi, 2003, Informed Trading, Investment, and Welfare, The Journal of Business 76, 439454.

Dye, R.A., 1988, Earnings Management in an Overlapping Generations Model, Journal of Accounting Research 26, 195-235.

— , 1990, Mandatory versus Voluntary Disclosures: The Cases of Financial and Real Externalities, The Accounting Review 65, 1-24.

— 2001, An Evaluation of Essays on Disclosure and the Disclosure Literature in Accounting, Journal of Accounting and Economics 32, 181-235.

, and S. Sridhar, 2002, Resource Allocation Effects of Price Reactions to Disclosures, Contemporary Accounting Research 19, 385-410.

— 2007, The Allocational Effects of the Precision of Accounting Estimates, Journal of Accounting Research 45, 731-769.

Easley, D., and M. O'Hara, 2004, Information and the Cost of Capital, The Journal of Finance 59, 15531583. 
Grossman, S.J., and J.E. Stiglitz, 1980, On the Impossibility of Informationally Efficient Markets, The American Economic Review 70, 393-408.

Hakansson, N.H., J.G. Kunkel, and J.A. Ohlson, 1982, Sufficient and Necessary Conditions for Information to Have Social Value in Pure Exchange, The Journal of Finance 37, 1169-1181.

Hayn, C., 1995, The Information Content of Losses, Journal of Accounting and Economics 20, 125-153.

Healy, P.M., and K.G. Palepu, 2001, Information Asymmetry, Corporate Disclosure, and the Capital Markets: A Review of the Empirical Disclosure Literature, Journal of Accounting and Economics 31, 405440 .

Hirshleifer, J., 1971, The Private and Social Value of Information and the Reward to Inventive Activity, The American Economic Review 61, 561-574.

Holmstrom, B., and J. Tirole, 1993, Market Liquidity and Performance Monitoring, The Journal of Political Economy 101, 678-709.

Hope, O.L.E.K., and W.B. Thomas, 2008, Managerial Empire Building and Firm Disclosure, Journal of Accounting Research 46, 591-626.

Hughes, J.S., J. Liu, and J. Liu, 2007, Information Asymmetry, Diversification, and Cost of Capital, The Accounting Review 82, 705-730.

Kanodia, C., 1980, Effects of Shareholder Information on Corporate Decisions and Capital Market Equilibrium, Econometrica 48, 923-953.

— and D. Lee, 1998, Investment and Disclosure: The Disciplinary Role of Periodic Performance Reports, Journal of Accounting Research 36, 33-55.

Kanodia, C., A. Mukherji, H. Sapra, and R. Venugopalan, 2000, Hedge Disclosures, Future Prices, and Production Distortions, Journal of Accounting Research 38, 53-82.

Kanodia, C., H. Sapra, and R. Venugopalan, 2004, Should Intangibles Be Measured: What Are the Economic Trade-Offs?, Journal of Accounting Research 42, 89-120.

Kanodia, C., R. Singh, and A.E. Spero, 2005, Imprecision in Accounting Measurement: Can It Be Value Enhancing?, Journal of Accounting Research 43, 487-519. 
Kunkel, J.G., 1982, Sufficient Conditions for Public Information to Have Social Value in a Production and Exchange Economy, The Journal of Finance 37, 1005-1013.

Kyle, A.S., 1985, Continuous Auctions and Insider Trading, Econometrica 53, 1315-1335.

Lambert, R., 2001, Contracting Theory and Accounting, Journal of Accounting and Economics 32, 3-87.

— C. Leuz, and R.E. Verrecchia, 2006, Information Asymmetry, Information Precision, and the Cost of Capital, working paper.

_ 2007, Accounting Information, Disclosure, and the Cost of Capital, Journal of Accounting Research 45, 385-420.

Leuz, C., and P.D. Wysocki, 2007, Economic Consequences of Financial Reporting and Disclosure Regulation: What Have We Learned?, Working Paper.

Levitt, A., 1998, The Importance of High Quality Accounting Standards, Accounting Horizons 12, 79-82.

Melumad, N.D., G. Weyns, and A. Ziv, 1999, Comparing Alternative Hedge Accounting Standards: Shareholders' Perspective, Review of Accounting Studies 4, 265-292.

Milgrom, P., and N. Stokey, 1982, Information, Trade Level and Common Knowledge, Journal of Economic Theory 26, 17-27.

Pae, S., 1999, Acquisition and Discretionary Disclosure of Private Information and Its Implications for Firms’ Productive Activities, Journal of Accounting Research 37, 465-474.

— , 2002, Discretionary Disclosure, Efficiency, and Signal Informativeness, Journal of Accounting and Economics 33, 279-311.

Sapra, H., 2002, Do Mandatory Hedge Disclosures Discourage or Encourage Excessive Speculation?, Journal of Accounting Research 40, 933-964.

— , and H.S. Shin, 2007, Do Derivative Disclosures Impede Sound Risk Management?, Working Paper.

Schlee, E.E., 2001, The Value of Information in Efficient Risk-Sharing Arrangements, The American Economic Review 91, 509-524. 
Sunder, S., 1989, Proof that in an Efficient Market, Event Studies can Provide no Systematic Guidance for Revision of Accounting Standards and Disclosure Policy for the Purpose of Maximizing Shareholder Wealth, Contemporary Accounting Research 5, 452-460.

Verdi, R., 2006, Financial Reporting Quality and Investment Efficiency, Working Paper.

Verrecchia, R.E., 1982, The Use of Mathematical Models in Financial Accounting, Journal of Accounting Research 20, 1-42.

— , 1983, Discretionary Disclosure, Journal of Accounting and Economics 5, 179-194.

— , 2001, Essays on Disclosure, Journal of Accounting and Economics 32, 97-180.

Watts, R.L., 1982, Discussion of the Use of Mathematical Models in Financial Accounting, Journal of Accounting Research 20, 48-55.

Wilson, R., 1968, The Theory of Syndicates, Econometrica 36, 119-132.

Yee, K.K., 2006, Earnings Quality and the Equity Risk Premium: A Benchmark Model, Contemporary Accounting Research 23, 833-877.

- 2007, Using Accounting Information for Consumption Planning and Equity Valuation, Review of Accounting Studies 12, 227-256.

\section{Appendix}

The following proofs involve Lemma 4 and 5. I state and prove them first.

Lemma 4. $f(\cdot)$ is a continuous function, $f^{-1}(\cdot)$ is the inverse function of $f(\cdot)$, and $f^{\prime}(\cdot)$ is the first derivative of $f(\cdot)$. If $f^{\prime}(x)>0(<0)$, then

$$
y>f(x) \Longleftrightarrow x<(>) f^{-1}(y)
$$

Proof of Lemma 4.

$$
\begin{aligned}
y>f(x) & \Longleftrightarrow y-f(x)>0 \\
& \Longleftrightarrow f\left(f^{-1}(y)\right)-f(x)>0
\end{aligned}
$$


By the Lagrange Mean Value theorem, there exists

$x_{0} \in\left(x, f^{-1}(y)\right)$ if $x<f^{-1}(y)$, or $x_{0} \in\left(f^{-1}(y), x\right)$ if $x>f^{-1}(y)$

such that

$$
f\left(f^{-1}(y)\right)-f(x)=f^{\prime}\left(x_{0}\right)\left(f^{-1}(y)-x\right)>0
$$

Since $f^{\prime}\left(x_{0}\right)>(<) 0$, thus

$$
f^{-1}(y)-x>(<) 0 \Longleftrightarrow x<(>) f^{-1}(y)
$$

Lemma 5. Suppose $x$ is a normally distributed random variable with mean zero and variance $\sigma^{2}$. If 1 $2 a \sigma^{2}>0$, then

$$
E\left[\exp \left(a x^{2}+b x+c\right)\right]=\frac{1}{\sqrt{1-2 a \sigma^{2}}} \exp \left(\frac{\frac{1}{2} b^{2} \sigma^{2}}{1-2 a \sigma^{2}}+c\right)
$$

Proof of Lemma 5. Since $x$ is a normally distributed random variable with mean zero and variance $\sigma^{2}$, and $1-2 a \sigma^{2}>0$

$$
\begin{aligned}
& E\left[\exp \left(a x^{2}+b x+c\right)\right]=\frac{1}{\sqrt{2 \pi \sigma^{2}}} \int_{-\infty}^{\infty} \exp \left(a x^{2}+b x+c\right) \exp \left(-\frac{1}{2} \frac{x^{2}}{\sigma^{2}}\right) d x \\
& \quad=\frac{1}{\sqrt{2 \pi \sigma^{2}}} \int_{-\infty}^{\infty} \exp \left(-\frac{1-2 a \sigma^{2}}{2 \sigma^{2}}\left(x^{2}-2 \frac{b \sigma^{2}}{1-2 a \sigma^{2}} x\right)+c\right) d x \\
& \quad=\frac{1}{\sqrt{2 \pi \sigma^{2}}} \int_{-\infty}^{\infty} \exp \left(-\frac{1}{2} \frac{\left(x-\frac{b \sigma^{2}}{1-2 a \sigma^{2}}\right)^{2}}{\frac{\sigma^{2}}{\left(1-2 a \sigma^{2}\right)}}\right) \exp \left(\frac{\frac{1}{2} b^{2} \sigma^{2}}{1-2 a \sigma^{2}}+c\right) d x \\
& \quad=\frac{1}{\sqrt{1-2 a \sigma^{2}}} \exp \left(\frac{\frac{1}{2} b^{2} \sigma^{2}}{1-2 a \sigma^{2}}+c\right) \int_{-\infty}^{\infty} \frac{1}{\sqrt{\frac{2 \pi \sigma^{2}}{\left(1-2 a \sigma^{2}\right)}}} \exp \left(-\frac{1}{2} \frac{\left(x-\frac{b \sigma^{2}}{1-2 a \sigma^{2}}\right)^{2}}{\frac{\sigma^{2}}{\left(1-2 a \sigma^{2}\right)}}\right) d x \\
& =\frac{1}{\sqrt{1-2 a \sigma^{2}}} \exp \left(\frac{\frac{1}{2} b^{2} \sigma^{2}}{1-2 a \sigma^{2}}+c\right)
\end{aligned}
$$

Proof of Lemma 1. First, I solve for the price $p(y)$, given new investors' conjecture about the firm's investment decision $k(y)$. Given their knowledge of $\beta$ and $y$, and their conjecture $k(y)$, new investors perceive that the firm's cash flow has a normal distribution with mean $E[\tilde{F} \mid(y, k(y))]$ and $\operatorname{Var}[\tilde{F} \mid(y, k(y))]$,

$$
\begin{aligned}
E[\tilde{F} \mid(y, k(y))] & =m\left(\mu_{0}+E[\tilde{\mu} \mid y]\right)+k E[\tilde{\mu} \mid y]-\frac{z}{2} k^{2} \\
\operatorname{Var}[\tilde{F} \mid(y, k(y))] & =(m+k)^{2} \operatorname{Var}[\tilde{\mu} \mid y]
\end{aligned}
$$


A representative new investor $i$ chooses her demand $D_{i}$ to maximize her expected utility by solving the following program $(P 1)$.

$$
\begin{aligned}
(P 1) \max _{D_{i}} E\left[U\left(W_{n}\right) \mid(y, k(y))\right] & \left.=-E\left[\exp \left(-\frac{1}{\tau_{n}} D_{i}(\tilde{F}-p)\right) \mid(y, k(y))\right]\right] \\
& =-\exp \left(-\frac{D_{i}}{\tau_{n}}\left(E[\tilde{F} \mid(y, k(y))]-p(y)-\frac{D_{i}}{2 \tau_{n}} \operatorname{Var}[\tilde{F} \mid(y, k(y))]\right)\right)
\end{aligned}
$$

The first-order condition gives the optimal demand function:

$$
D_{i}^{*}=\tau_{n} \frac{E[\tilde{F} \mid(y, k(y))]-p(y)}{\operatorname{Var}[\tilde{F} \mid(y, k(y))]}
$$

The second-order condition is $-\frac{\operatorname{Var}[\tilde{F} \mid(y, k(y))]}{\tau_{n}}<0$, guaranteeing that $D_{i}^{*}$ is the maximum solution.

Since the per capita supply of shares is normalized to one unit, market clearing requires that

$$
1=\int_{0}^{1} D_{i}^{*} d i=\tau_{n} \frac{E[\tilde{F} \mid(y, k(y))]-p(y)}{\operatorname{Var}[\tilde{F} \mid(y, k(y))]}
$$

Thus, I get the trading price

$$
p(y)=E[\tilde{F} \mid(y, k(y))]-\frac{1}{\tau_{n}} \operatorname{Var}[\tilde{F} \mid(y, k(y))]
$$

Second, anticipating the trading price $p(y)$, the firm makes the investment decision $k(y)$ to maximize the stock price by solving the following program.

$$
\begin{aligned}
(P 2) \max _{k(y)} E[p(y) \mid y] & =p(y) \\
& =E[\tilde{F} \mid(y, k(y))]-\frac{1}{\tau_{n}} \operatorname{Var}[\tilde{F} \mid(y, k(y))] \\
& =m \mu_{0}+(m+k(y)) E[\tilde{\mu} \mid y]-\frac{z}{2} k^{2}(y)-\frac{(m+k(y))^{2} \operatorname{Var}[\tilde{\mu} \mid y]}{\tau_{n}}
\end{aligned}
$$

The first-order condition gives the optimal new investment function:

$$
k(y)=\frac{E[\tilde{\mu} \mid y]}{z+\frac{2}{\tau_{n}} \operatorname{Var}[\tilde{\mu} \mid y]}-\frac{\frac{2}{\tau_{n}} \operatorname{Var}[\tilde{\mu} \mid y]}{z+\frac{2}{\tau_{n}} \operatorname{Var}[\tilde{\mu} \mid y]} m
$$

The second-order condition is $-z-\frac{2 \operatorname{Var}[\tilde{\mu} \mid y]}{\tau_{n}}<0$, guaranteeing that $k(y)$ is the maximum solution. 
Therefore,

$$
\begin{aligned}
p(y)= & E[\tilde{F} \mid y]-\frac{1}{\tau_{n}} \operatorname{Var}[\tilde{F} \mid y] \\
E[\tilde{F} \mid y]= & m \mu_{0}-\frac{2 z m^{2} \operatorname{Var}[\tilde{\mu} \mid y]^{2}}{\left(z \tau_{n}+2 \operatorname{Var}[\tilde{\mu} \mid y]\right)^{2}}+\frac{z m \tau_{n}\left(z \tau_{n}+4 \operatorname{Var}[\tilde{\mu} \mid y]\right)}{\left(z \tau_{n}+2 \operatorname{Var}[\tilde{\mu} \mid y]\right)^{2}} E[\tilde{\mu} \mid y]+ \\
& +\frac{\tau_{n}\left(z \tau_{n}+4 \operatorname{Var}[\tilde{\mu} \mid y]\right)}{2\left(z \tau_{n}+2 \operatorname{Var}[\tilde{\mu} \mid y]\right)^{2}} E[\tilde{\mu} \mid y]^{2} \\
\operatorname{Var}[\tilde{F} \mid y]= & \frac{z^{2} m^{2} \tau_{n}^{2} \operatorname{Var}[\tilde{\mu} \mid y]}{\left(z \tau_{n}+2 \operatorname{Var}[\tilde{\mu} \mid y]\right)^{2}}+\frac{2 z m \tau_{n}^{2} \operatorname{Var}[\tilde{\mu} \mid y]}{\left(z \tau_{n}+2 \operatorname{Var}[\tilde{\mu} \mid y]\right)^{2}} E[\tilde{\mu} \mid y]+ \\
& +\frac{\tau_{n}^{2} \operatorname{Var}[\tilde{\mu} \mid y]}{\left(z \tau_{n}+2 \operatorname{Var}[\tilde{\mu} \mid y]\right)^{2}} E[\tilde{\mu} \mid y]^{2}
\end{aligned}
$$

Proof of Lemma 2. The expected mean, variance, and price are

$$
\begin{aligned}
E & \equiv E[E[\tilde{F} \mid y]]=m \mu_{0}-\frac{4 \alpha z m^{2}+\beta \tau_{n}\left(4+(\alpha+\beta) z \tau_{n}\right)}{2 \alpha\left(2+z \tau_{n}(\alpha+\beta)\right)^{2}} \\
V & \equiv E[\operatorname{Var}[\tilde{F} \mid y]]=\frac{\left(\beta+\alpha^{2} z^{2} m^{2}+\alpha \beta z^{2} m^{2}\right) \tau_{n}^{2}}{\alpha\left(2+z \tau_{n}(\alpha+\beta)\right)^{2}} \\
P & \equiv E\left[E[\tilde{F} \mid y]-\frac{1}{\tau_{n}} \operatorname{Var}[\tilde{F} \mid y]\right]=E-\frac{1}{\tau_{n}} V
\end{aligned}
$$

By taking the partial derivative of equation A-9 and A-11 with respect to $\beta$, and solving for $\frac{\partial E}{\partial \beta}>0$ and $\frac{\partial P}{\partial \beta}>0$, I get

$$
\begin{aligned}
& \frac{\partial E}{\partial \beta}=\frac{\operatorname{tn}\left(8+\alpha z\left(8 z m^{2}+6 \tau_{n}+\beta z \tau_{n}^{2}\right)\right)}{2 \alpha\left(2+\alpha z \tau_{n}+\beta z \tau_{n}\right)^{3}}>0 \\
& \frac{\partial P}{\partial \beta}=\frac{\tau_{n}\left(2+\alpha z\left(2 z m^{2}+\tau_{n}\right)\right)}{2 \alpha\left(2+\alpha z \tau_{n}+\beta z \tau_{n}\right)^{2}}>0
\end{aligned}
$$

By taking the partial derivative of equation A-10 with respect to $\beta$ and solving for $\frac{\partial V}{\partial \beta}>0$, I get the solution $\left\{\alpha<\alpha^{*}(z), \beta<\beta^{*}(z)\right\}$ where

$$
\begin{aligned}
& \alpha^{*}(z)=\frac{2 z m^{2}+\tau_{n}}{2 z^{2} m^{2} \tau_{n}}+\frac{1}{2} \sqrt{\frac{4 z^{2} m^{4}+12 z m^{2} \tau_{n}+\tau_{n}^{2}}{z^{4} m^{4} \tau_{n}^{2}}} \\
& \beta^{*}(z)=\frac{2+2 \alpha z^{2} m^{2}+\alpha z \tau_{n}-\alpha^{2} z^{3} m^{2} \tau_{n}}{z \tau_{n}+\alpha z^{3} m^{2} \tau_{n}}
\end{aligned}
$$

Both the cutoffs $\alpha^{*}(z)$ and $\beta^{*}(z)$ are decreasing in $z$, because

$$
\begin{aligned}
\frac{\partial \alpha^{*}(z)}{\partial z} & =-\frac{1}{z^{3} m^{2} \tau_{n}}\left(z m^{2}+\tau_{n}+\frac{\left(2 z^{2} m^{4}+9 z m^{2} \tau_{n}+\tau_{n}^{2}\right)}{\sqrt{4 z^{2} m^{4}+12 z m^{2} \tau_{n}+\tau_{n}^{2}}}\right)<0 \\
\frac{\partial \beta^{*}(z)}{\partial z} & =-\frac{2\left(1+2 \alpha z^{2} m^{2}+\alpha^{2} z^{3} m^{2}\left(z m^{2}+2 \tau_{n}\right)\right)}{\tau_{n}\left(z+\alpha z^{3} m^{2}\right)^{2}}<0
\end{aligned}
$$


Thus, by Lemma 4

$$
\begin{aligned}
\left\{\alpha<\alpha^{*}(z), \beta<\beta^{*}(z)\right\} & \Longleftrightarrow\left\{z<z_{\alpha}(\alpha), z<z_{\beta}(\beta)\right\} \\
& \Longleftrightarrow z<z^{*}
\end{aligned}
$$

where $z_{\alpha}(\alpha)$ and $z_{\beta}(\beta)$ are the inverse functions of $\alpha^{*}(z)$ and $\beta^{*}(z)$ evaluated at $\alpha$ and $\beta$, respectively, and

$$
z^{*}=\min \left(z_{\alpha}(\alpha), z_{\beta}(\beta)\right)
$$

Proof of Lemma 3. Lemma 3 is proved by taking the limit $(z \rightarrow \infty, z \rightarrow 0, m \rightarrow 0)$ of the conditions in Lemma 2.

Proof of Proposition 1. Cost of capital is defined as

$$
E[\tilde{R}]=\frac{E-P}{P}
$$

By equations A-9, A-10, and A-11,

$$
E[\tilde{R}]=\frac{2\left(\beta+\alpha^{2} z^{2} m^{2}+\alpha \beta z^{2} m^{2}\right) \tau_{n}}{\left(2+\alpha z \tau_{n}+\beta z \tau_{n}\right)\left(\beta \tau_{n}+2 \alpha^{2} z m \tau_{n} \mu_{0}+2 \alpha m\left(2 \mu_{0}+\beta z \tau_{n} \mu_{0}-z m\right)\right)}
$$

By taking the partial derivative of equation (A-17) with respect to $\beta$, and solving for $\frac{\partial E[\tilde{R}]}{\partial \beta}>0$ with respect to $\left\{\alpha, \beta, \mu_{0}\right\}$, I obtain the solution $\left\{\alpha<\alpha^{*}(z), \beta<\beta^{*}(z), \mu_{0}>\mu_{0}^{*}\right\}$ where $\alpha^{*}(z)$ and $\beta^{*}(z)$ are the same as in expressions A-12 and A-13, and

$$
\mu_{0}^{*}=\frac{z\left(\beta^{2} \tau_{n}^{2}+\alpha m^{2}\left(4+4 \alpha z\left(z m^{2}+\tau_{n}\right)+(\alpha+\beta)^{2} z^{2} \tau_{n}^{2}\right)\right)}{2 \alpha m\left(2+\alpha z \tau_{n}+\beta z \tau_{n}\right)\left(2+(\alpha-\beta) z \tau_{n}+\alpha z^{2} m^{2}\left(2-(\alpha+\beta) z \tau_{n}\right)\right)}
$$

According to the proof of Lemma 2,

$$
\left\{\alpha<\alpha^{*}(z), \beta<\beta^{*}(z), \mu_{0}>\mu_{0}^{*}\right\} \Longleftrightarrow\left\{z<z^{*}, \mu_{0}>\mu_{0}^{*}\right\}
$$

Therefore, $\frac{\partial E[\tilde{R}]}{\partial \beta}<0 \Longleftrightarrow\left\{\left\{z>z^{*}\right\},\left\{\mu_{0}<\mu_{0}^{*}\right\}\right\}$.

Proof of Corollary 1. Corollary 1 is proved by taking the limit $(z \rightarrow \infty, z \rightarrow 0, m \rightarrow 0)$ of the conditions in Proposition 1. 
Proof of Proposition 2. Current investors' welfare is

$$
\begin{aligned}
E\left[U\left(W_{c}\right)\right]= & E\left[E\left[U\left(W_{c}\right) \mid y\right]\right] \\
= & -E\left[E\left[\exp \left(-\frac{1}{\tau_{c}} p\right) \mid y\right]\right] \\
= & -E\left[\exp \left(-\frac{1}{\tau_{c}} p(y)\right)\right] \\
= & -E\left[\operatorname { e x p } \left(-\frac{1}{\tau_{c}}\left(m \mu_{0}-\frac{z m^{2}}{2+\alpha z \tau_{n}+\beta z \tau_{n}}+\frac{\beta z m \tau_{n}}{2+\alpha z \tau_{n}+\beta z \tau_{n}} y+\right.\right.\right. \\
& \left.\left.\left.+\frac{\beta^{2} \tau_{n}}{2(\alpha+\beta)\left(2+\alpha z \tau_{n}+\beta z \tau_{n}\right)} y^{2}\right)\right)\right] \\
= & M_{1} \exp \left(M_{2}\right)
\end{aligned}
$$

Where

$$
\begin{aligned}
M_{1} & =-\frac{1}{\sqrt{1+\frac{\beta \tau_{n}}{\alpha \tau_{c}\left(2+\alpha z t_{n}+\beta z \tau_{n}\right)}}} \\
M_{2} & =\frac{m^{2}\left(2 \alpha z \tau_{c}+\beta z \tau_{n}\right)}{2 \tau_{c}\left(2 \alpha \tau_{c}+\beta \tau_{n}+\alpha^{2} z \tau_{c} \tau_{n}+\alpha \beta z \tau_{c} \tau_{n}\right)}-\frac{m \mu_{0}}{\tau_{c}}
\end{aligned}
$$

The last step from equation A-19 to equation A-20 involves Lemma 5. By taking the partial derivative of equation (A-20) with respect to $\beta$ and solving for $\frac{\partial E\left[U\left(W_{c}\right)\right]}{\partial \beta}>0$, I get $\left\{\left\{\tau_{c} \geq \frac{\tau_{n}}{2}\right\},\left\{\tau_{c}<\frac{\tau_{n}}{2}, m<\right.\right.$ $\left.\left.m_{c}^{*}(z)\right\}\right\}$, where

$$
m_{c}^{*}(z)=\sqrt{\frac{\left(2+\alpha z \tau_{n}\right)\left(2 \alpha \tau_{c}+\beta \tau_{n}+\alpha^{2} z \tau_{c} \tau_{n}+\alpha \beta z \tau_{c} \tau_{n}\right)}{\alpha^{2} z^{2}\left(\tau_{n}-2 \tau_{c}\right)\left(2+\alpha z \tau_{n}+\beta c \tau_{n}\right)}}
$$

When $\tau_{c}<\frac{\tau_{n}}{2}, m_{c}^{*}(z)$ decreases in adjustment cost $z$ because

$$
\frac{\partial m_{c}^{*}(z)}{\partial z}=-H \sqrt{\frac{\alpha^{2} z^{2}\left(\tau_{n}-2 \tau_{c}\right)\left(2+\alpha z \tau_{n}+\beta c \tau_{n}\right)}{\left(2+\alpha z \tau_{n}\right)\left(2 \alpha \tau_{c}+\beta \tau_{n}+\alpha^{2} z \tau_{c} \tau_{n}+\alpha \beta z \tau_{c} \tau_{n}\right)}}<0
$$

where

$$
\begin{aligned}
H & =\frac{1}{2 \alpha^{2} z^{3}\left(\tau_{n}-2 \tau_{c}\right)\left(2+(\alpha+\beta) z \tau_{n}\right)^{2}}\left(16 \alpha \tau_{c}+8 \beta \tau_{n}\right. \\
& +z \tau_{n}\left(20 \alpha^{2} \tau_{c}+16 \alpha \beta \tau_{c}+8 \alpha \beta \tau_{n}+6 \beta^{2} \tau_{n}+8 \alpha^{3} z \tau_{c} \tau_{n}+\alpha^{4} z^{2} \tau_{c} \tau_{n}^{2}\right. \\
& \left.\left.+\alpha \beta z \tau_{n}\left(12 \alpha \tau_{c}+4 \beta \tau_{c}+2 \alpha \tau_{n}+2 \alpha^{2} z \tau_{n}+\alpha \beta z \tau_{c} \tau_{n}\right)\right)\right) \\
& >0
\end{aligned}
$$

By Lemma 4 and denoting $z_{c}^{*}$ as the inverse function of $m_{c}^{*}(z)$ evaluated at $m$, we have

$$
m<m_{c}^{*}(z) \Longleftrightarrow z<z_{c}^{*}
$$


Therefore,

$$
\frac{\partial E\left[U\left(W_{c}\right)\right]}{\partial \beta}>0 \Longleftrightarrow\left\{\left\{\tau_{c} \geq \frac{\tau_{n}}{2}\right\},\left\{\tau_{c}<\frac{\tau_{n}}{2}, z<z_{c}^{*}\right\}\right\}
$$

Proof of Corollary 2. Corollary 2 is proved by taking the limit $(z \rightarrow \infty, z \rightarrow 0, m \rightarrow 0)$ of the conditions in Proposition 2.

Proof of Proposition 3. New investors' welfare is

$$
\begin{aligned}
E\left[U\left(W_{n}\right)\right] & =E\left[E\left[U\left(W_{n}\right) \mid y\right]\right] \\
& =-E\left[E\left[\exp \left(-\frac{1}{\tau_{n}}(\tilde{F}-p)\right) \mid y\right]\right] \\
& =-E\left[\exp \left(-\frac{1}{\tau_{n}}\left((E[\tilde{F} \mid(y, k(y))]-p(y))-\frac{1}{2 \tau_{n}} \operatorname{Var}[\tilde{F} \mid(y, k(y))]\right)\right)\right] \\
& =-E\left[\exp \left(-\frac{1}{2\left(\tau_{n}\right)^{2}} \operatorname{Var}[\tilde{F} \mid(y, k(y))]\right)\right] \\
& =-E\left[\exp \left(-\frac{1}{2\left(\tau_{n}\right)^{2}}(m+k)^{2} \operatorname{Var}[\tilde{\mu} \mid y]\right)\right] \\
& =N_{1} \exp \left(N_{2}\right)
\end{aligned}
$$

where

$$
\begin{aligned}
& N_{1}=\frac{1}{\sqrt{1+\frac{\beta}{\alpha\left(2+\alpha z \tau_{n}+\beta z \tau_{n}\right)^{2}}}} \\
& N_{2}=-\frac{\alpha(\alpha+\beta) z^{2} m^{2}}{2\left(\beta+\alpha^{3} z^{2} \tau_{n}^{2}+2 \alpha^{2} z \tau_{n}\left(2+\beta z \tau_{n}\right)+\alpha\left(2+\beta z \tau_{n}\right)^{2}\right)}
\end{aligned}
$$

The last step from equation A-25 to A-26 involves Lemma 5. By taking the partial derivative of equation (A-26) with respect to $\beta$ and solving for $\frac{\partial E\left[U\left(W_{n}\right)\right]}{\partial \beta}>0$. The solution consists of four regions: $\{\beta>\alpha, z<$ $\left.z_{n}^{*}\right\},\left\{\beta>\alpha, z_{n}^{*}<z<z_{n}^{* *}, m<m_{n}^{*}\right\},\left\{\beta \leq \alpha, z<z_{n}^{*}\right\}$, and $\left\{\beta \leq \alpha, z>z_{n}^{*}, m<m_{n}^{*}\right\}$ where

$$
\begin{aligned}
z_{n}^{*} & =\frac{\sqrt{3}}{(\alpha+\beta) \tau_{n}} \\
z_{n}^{* *} & =\frac{2}{(\beta-\alpha) \tau_{n}} \\
m_{n}^{*} & =\frac{\left(2+\alpha z t_{n}-\beta z \tau_{n}\right)\left(4 \alpha+\beta+\alpha z \tau_{n}(\alpha+\beta)\left(4+z \tau_{n}(\alpha+\beta)\right)\right)}{\alpha^{2} z^{2}\left(2+\alpha z t_{n}+\beta z \tau_{n}\right)\left(\alpha^{2} z^{2} \tau_{n}^{2}+2 \alpha \beta z^{2} \tau_{n}^{2}+\beta^{2} z^{2} \tau_{n}^{2}-3\right)}
\end{aligned}
$$

Proof of Corollary 3. Corollary 3 is proved by taking the $\operatorname{limit}(z \rightarrow \infty, z \rightarrow 0, m \rightarrow 0)$ of the conditions in Proposition 3. 


\section{Tables}

Table 1: Effects of Disclosure Quality on the Mean and Variance of the Firm's Cash Flow

\begin{tabular}{|c|c|c|}
\hline Economies $($ Cash Flow $\tilde{F})$ & Mean E & Variance $V$ \\
\hline Pure Exchange $\left(\mu_{0}+\tilde{\mu}\right)$ & Constant & Decrease \\
\hline CRTS $\left(m\left(\mu_{0}+\tilde{\mu}\right)+k \tilde{\mu}\right)$ & Increase & Increase \\
\hline No Endowment $\left(k \tilde{\mu}-\frac{z}{2} k^{2}\right)$ & Increase & Increase/Decrease \\
\hline General Economy $\left(m\left(\mu_{0}+\tilde{\mu}\right)+k \tilde{\mu}-\frac{z}{2} k^{2}\right)$ & Increase & Increase/Decrease \\
\hline
\end{tabular}

Table 2: Effects of Disclosure Quality on Cost of Capital and Investors' Welfare

\begin{tabular}{|c|c|c|c|}
\hline Economies & $\begin{array}{l}\text { Cost of } \\
\text { Capital }\end{array}$ & $\begin{array}{c}\text { Current Investors' } \\
\text { Welfare }\end{array}$ & $\begin{array}{c}\text { New Investors } \\
\text { Welfare }\end{array}$ \\
\hline Pure Exchange & Decrease & Increase/Decrease & Decrease \\
\hline CRTS & Increase & Increase & Increase \\
\hline No Endowment & Decrease & Increase & Increase/Decrease \\
\hline General Economy & Increase/Decrease $^{\curvearrowright}$ & Increase/Decrease ${ }^{\natural}$ & Increase/Decrease \\
\hline
\end{tabular}

